العمر البيداجوجي والتكنولوجي: هل يكفي لتغيير نمط التدريس لدى أعضاء هيئة التدريس بالجامعات؟

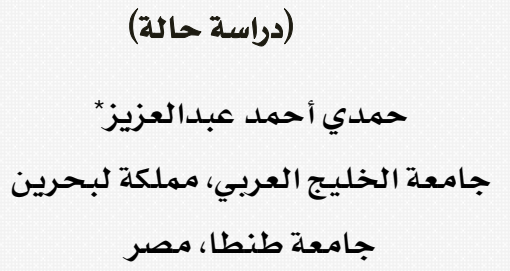

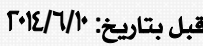

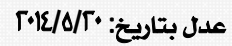

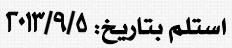

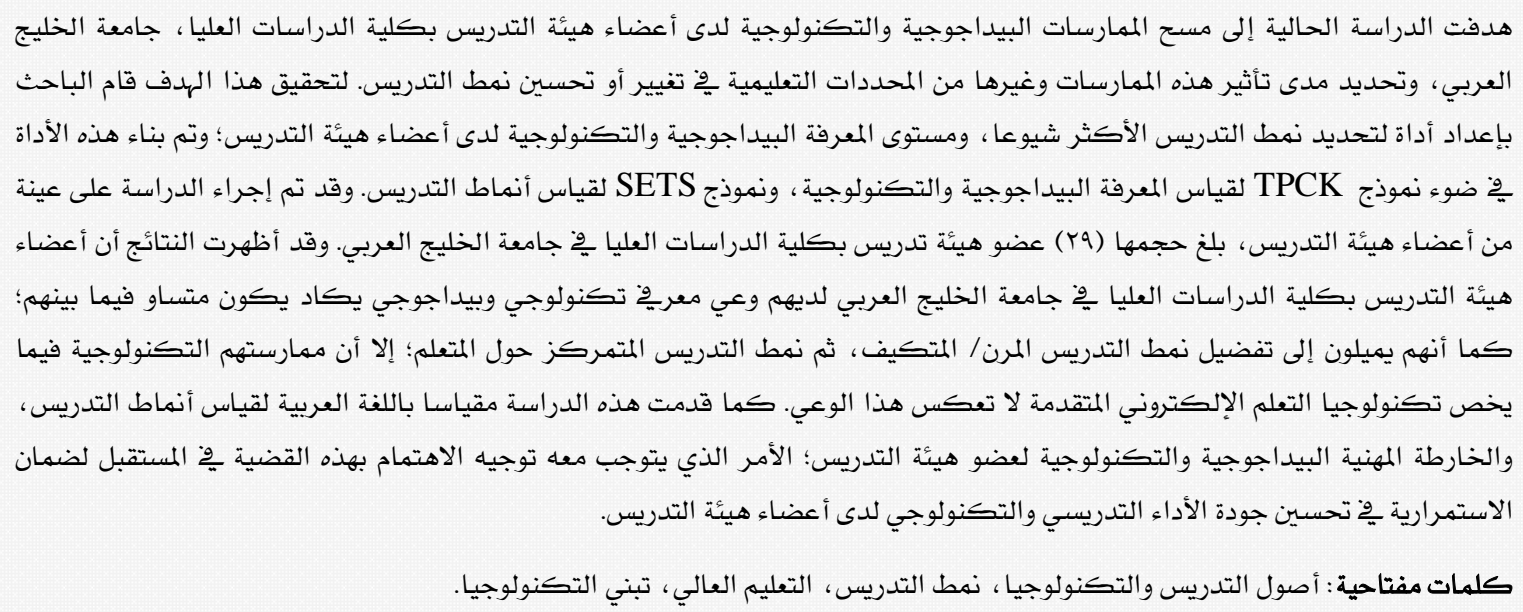

\title{
Pedagogical and Technological Age: Is it Sufficient to Change Teaching Style among Faculty M embers? (A Case Study)
}

\author{
Hamdy A. A bdelaziz* \\ Arabian Gulf University, Kingdom of Bahrain \\ Tanta University, Eygpt
}

The aim of this study was to explore the technological and pedagogical practices that are adopted by faculty members at the college of graduate studies, Arabian Gulf University; and to determine the impact of these practices and other determinants on changing or improving teaching style. To achieve this purpose, the researcher developed an instrument to determine the common teaching style and technological and pedagogical knowledge among a sample of 29 full-time faculty members. The instrument was developed based on the Technological and Pedagogical Content Knowledge (TPCK) model and the Staffordshire Evaluation of Teaching Styles (SETS). The results showed that faculty members at the college of the graduate studies have equal pedagogical and technological awareness. They also tend to prefer the all-round flexible and adaptable teaching style, and student-centered sensitive teaching style, but their technological practices do not reflect these styles. Based on these findings, a set of strategic educational recommendations are mentioned to increase the probability of adopting and applying technological and pedagogical change in higher education institutions.

Keyw ords: Pedagogical practices, teaching style, higher education, technology adoption.

*hamdyaaa@agu.edu.bh 
تجريب مداخل حديثة لتأهيله وتدرييه، وتزويده بالمهارات

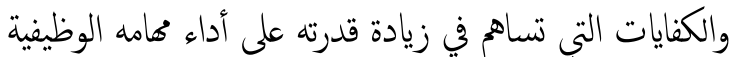

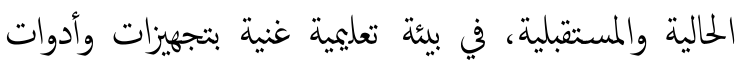

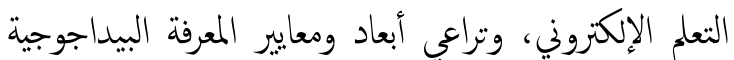

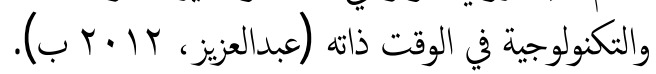
والمتنابع لبرامج تدريب وتطوير الأكاديمين يجد أنها تتوحد في

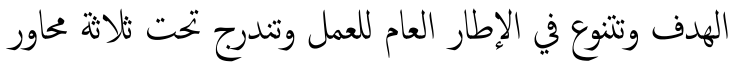

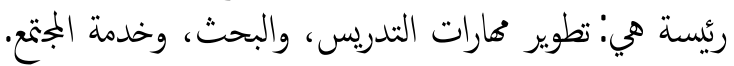

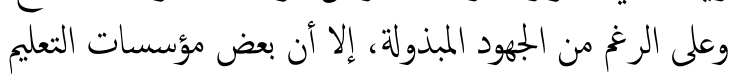

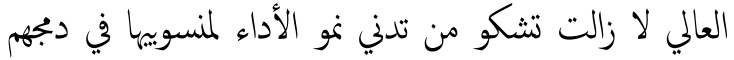

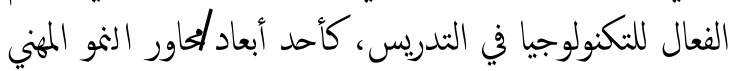

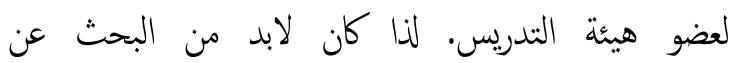

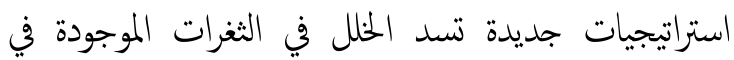
برامج الندريب والتنمية المهنية، وتزيد من كفاءة أعضاء الهيئة

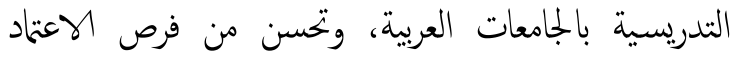

$$
\text { المؤسسي والأكاديي لهذه المؤسسات. }
$$

وتساهم التنمية المهنية لأعضاء هيئة التدريس في مؤسسات التعليم العالي في تطوير الأداء طبقا للمداخل والأساليب التبنة والتطبيقات الحديثة في التدريس، وزيادة المشاركة والتفاعل

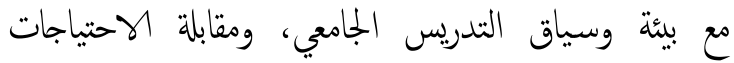

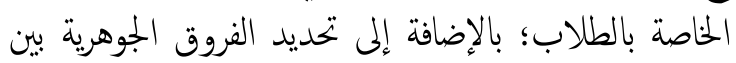

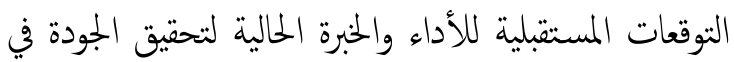
أداء أعضاء هيئة التدريس من خلال تطبيقات وتصميهات جديدة في الندريس، ومعارف ومحارات تكنولوجية جديدة، وعلاقات تفاعل جديدة مع الطلاب.كما تساهم التنمية المهنية لأعضاء هيئة التدريس بمؤسسات التعليم العالي في تقعيل

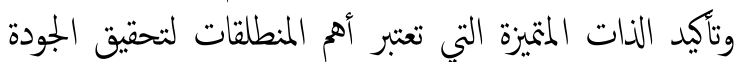

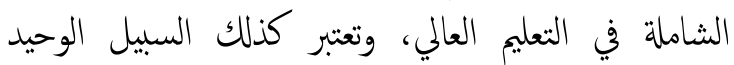
للتطوير المنظومي لأداء مؤسسات التعليم العالي (الجبالي، النيا، . (r..r

وتثأثر المارسات التدريسية سواء آكانت جامعية أو قبل

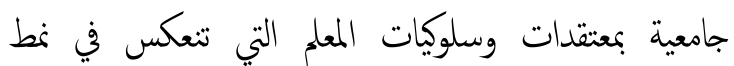
التدريس المفضل. فيمكن أن يوجه عضو هيئة التدريس

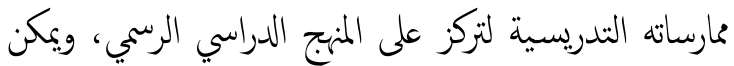

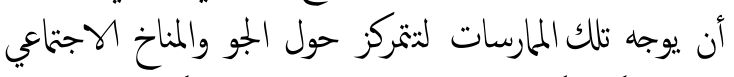
التفاعلي، كما يككن أن توجه تلك المارسات لتتمركز حول المتعلم
تستمد الجامعات ومؤسسات التعليم العالي أهيتها مما تقدمه من

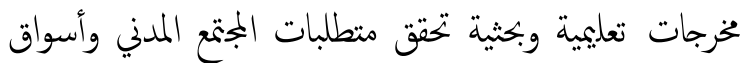

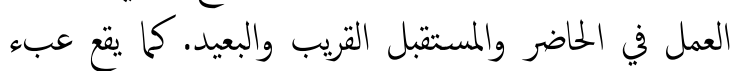

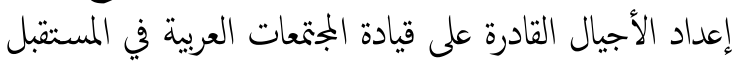

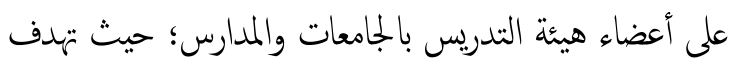
الجامعات ومؤسسات التعليم العالي وقبل الجامعي إلى إنتاج إنتاج

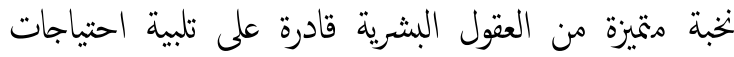
الدول والارنقاء بنهضتها.

ومع التطور المستمر الذي تشهده النهضة التكنولوجية في القرن الحادي والعشرين وابحت مهنة التدريس بمؤسسات النعليم العالي في الدول العربية صعوبة في تحديد وتفعيل أساس معرفي

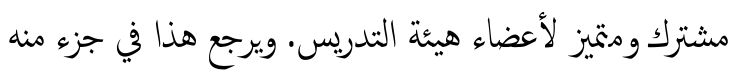

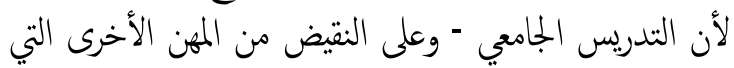

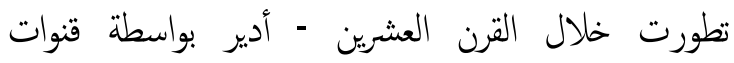
سياسية بدلا من أن يديره هيئات هنية مشتغلة بوض العنمين

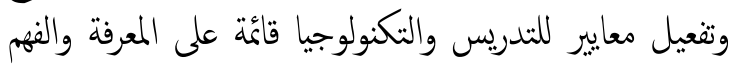
والممارسة الجيدة، أن الجامعات في القرن الحادي (Diaz et al., 2009)

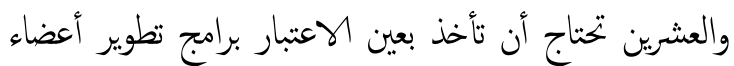

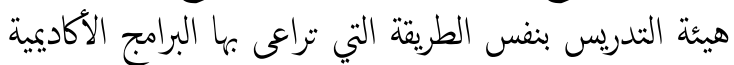
من أجل الأجيال المعاصرة من المتعلمين في الألفية الثالثة. وتعد ثورة تقنية المعلومات والاتصالات، وما نتج عنها من

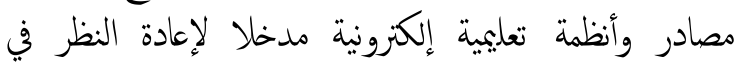

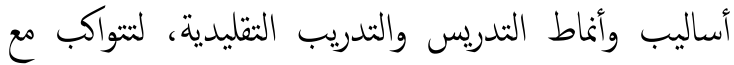

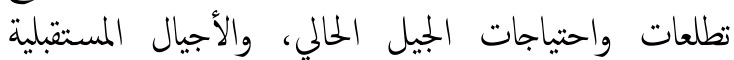
بالمجتمعات العربية - التي تنعايش مع هذه التقنيات التيل بشكل

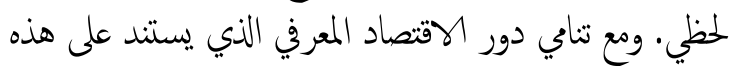

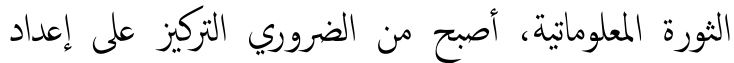

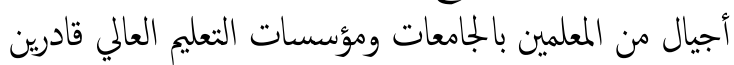

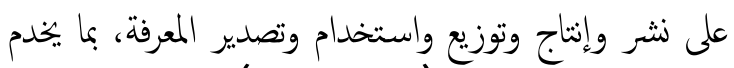

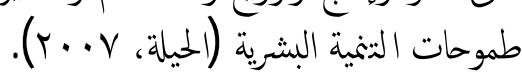
إن بناء وتكوين ججتعات المعرفة الجامعية القادرة على توظيف

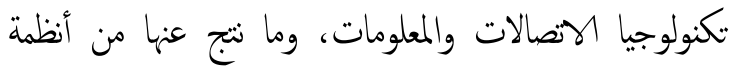

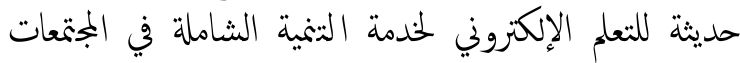
العربية أمرا يتطلب من المتخصصين في إعداد المعلم الجامعي

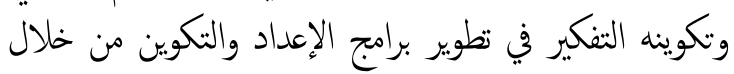


الأمر الذي يتطلب التدخل السريع لسد هذه الفجوة لتمكين

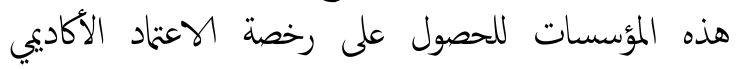
والمؤسسي، ورغز توافر محاولات لتقديم برامج التنمية المهنية

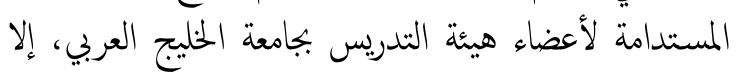

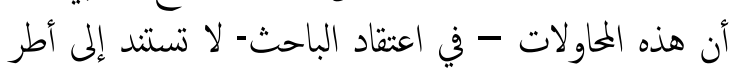

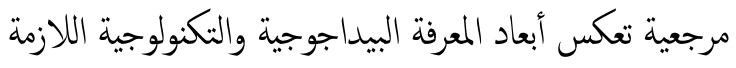

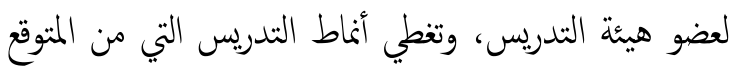

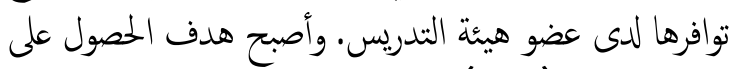

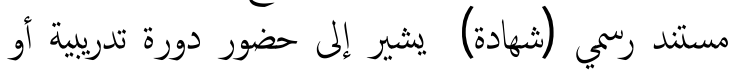

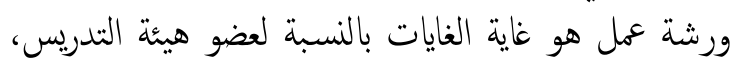

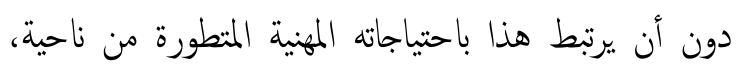
واحتياجات النمو والاعتماد المؤسسي من ناحية أخرى. وعليه

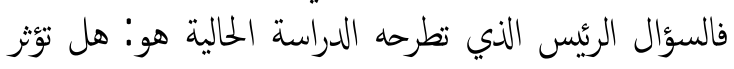

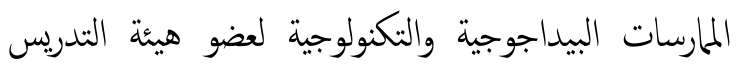

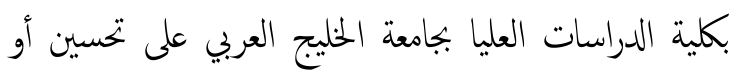
تغيير نمط التدريس أم هو عكس ذلك؟ ليك الكي

\section{أسئة الدراسة}

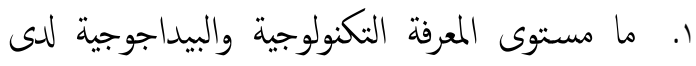
أعضاء هيئة التدريس بكلية الدراسات العليا، جامعة التعنة

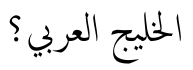

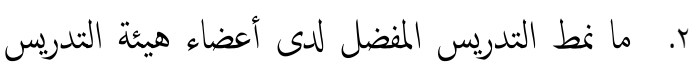

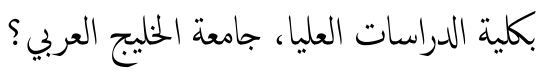

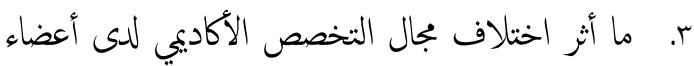

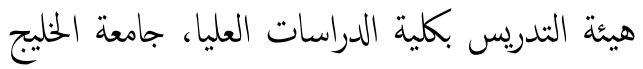

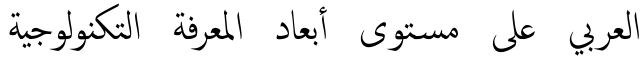

$$
\text { والبيداجوجية؟ }
$$

ع. ما أثر اختلاف الدرجة العلمية الأكاديمية بين أعضاء

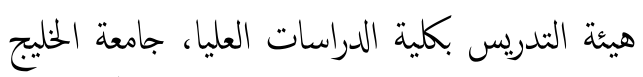

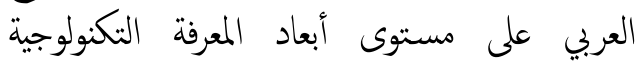

$$
\text { والبيداجوجية لديهم؟ }
$$

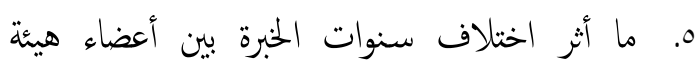

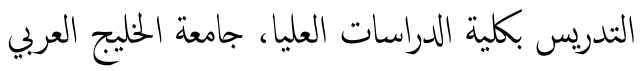

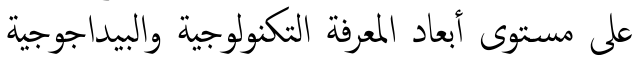
لديهم
(Opdenakker \& Van Damme, 2006) المعتقدات التدريسية (حول التدريس) تعد عاملا هما لدفن

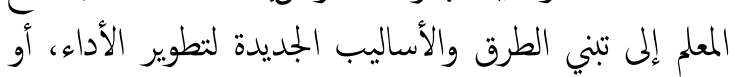

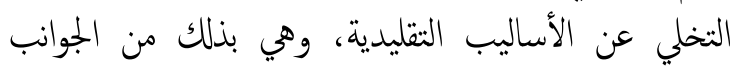

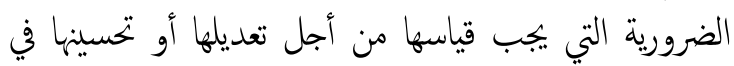

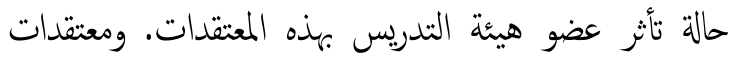
عضو هيئة التدريس هي تلك العوامل الوجدانية التي تقود

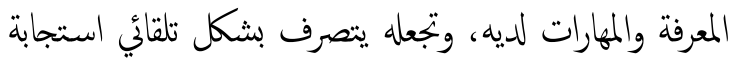

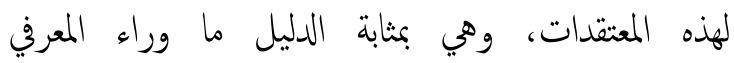
Meta-Cognitive Guide

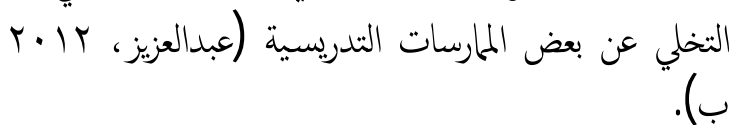

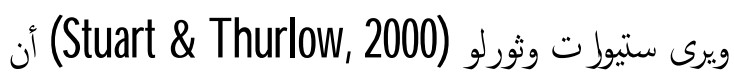
فهم المعتقدات التي تشكل عملية اتخاذ القرار للمعلم، خطوة

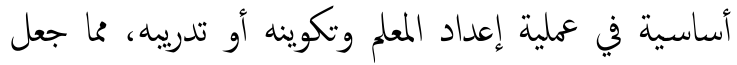

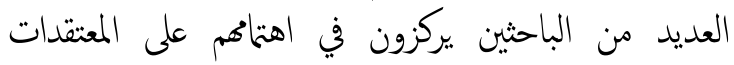

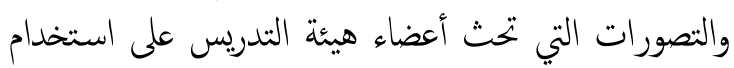

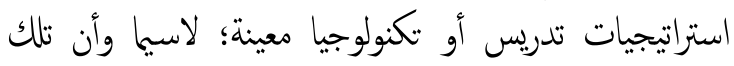

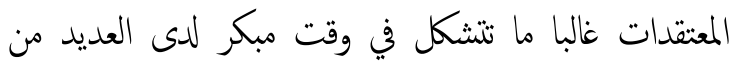
أعضاء هيئة التدريس، وتكون صعبة التغيير، وربما تكون خاطئة وتحتاج إلى تعديل في بعض الثربس، وتكون الأحيان. ومن هنا برزت أهمية الدراسة الحالية التي تسعى إلى تحديد

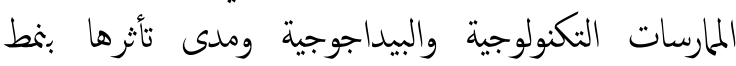
التدريس لدى أعضاء هيئة التدريس بالجامعات العربية، تمهيدا

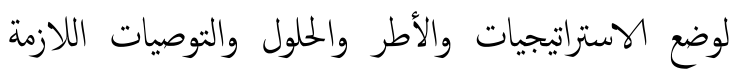

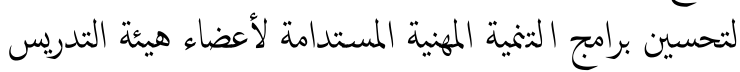
بالجامعات العربية.

\section{مشكلة الدراسة - مشك}

على الرغز من سعي الجامعات ومؤسسات التعليم العالي

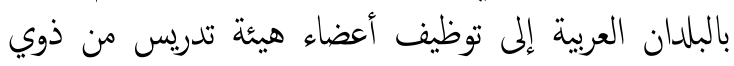
الكفاءة في التدريس والبحث وخدمة الجمتع، إلا أن تقارير

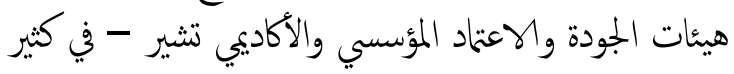

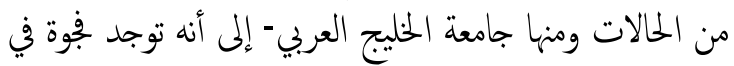

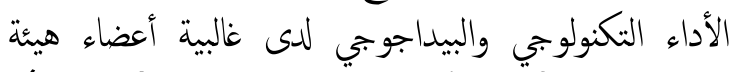
(Henard, 2009; Krause, Barrie, \& Scott, التدريس الأيكوجيس .2012; The Higher Education Academy, 2003) 
1. تمديد مستوى المعرفة التكنولوجية والبيداجوجية لدى أعضاء هيئة التدريس بكلية الدراسات العليا، جامعة الخنيج العربي.

r. الكشف عن نمط التدريس المفضل لدى أعضاء هيئة

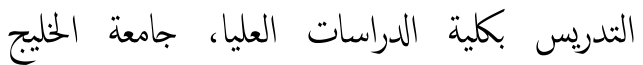

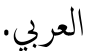
r. الكشف عن أثر اختلاف مجال التخصص الأكاديمي

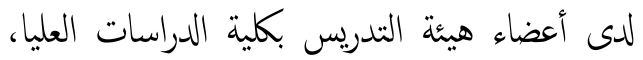
جامعة الخليج العربي على مستوى أبعاد المعرفة المئه التكنولوجية والبيداجوجية.

ع. الكشف عن أثر اختلاف الدرجة العلمية الأكاديمية بين أعضاء هيئة التدريس بكلية الدراسات العليا، جامعة الخليج العربي على مستوى أبعاد المعرفة التكنولوجية والبيداجوجية لديهم. 0. الكشف عن أثر اختلاف سنوات الخبرة بين أعضاء

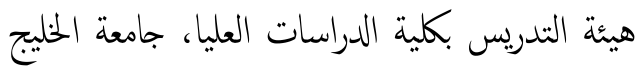
العربي على مستوى أبعاد المعرفة التكنولوجية

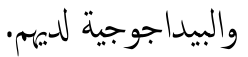
1، تحديد أثر اختلاف مجال التخصص الأكاديمي بين

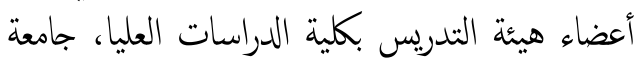
الخيج العربي على نمط التدريس المفضل لديهيه. تحديد أثر اختلاف الدرجة العلمية الأكاديمية بين

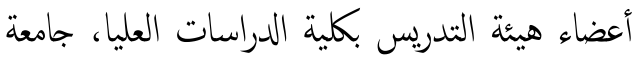
الخليج العربي على نمط الندريس المفضل لديهم.

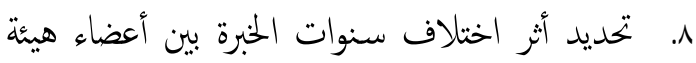

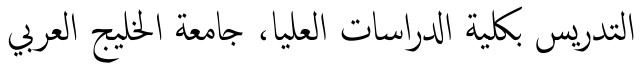
على نمط التدريس المفضل لديهم. 9. الكشف عن أثر مستوى المعرفة التكنولوجية والبيداجوجية على أنماط التدريس لدى أعضاء هيئة التدريس بجامعة الخنيج العربي.

الإطار النظري والدراسات السابقة أهمية المعرفة التكنولوجية والبيداجوجية لأعضاء هيئة التدريس

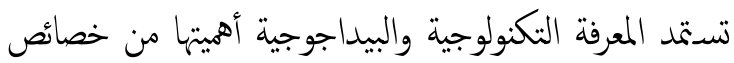

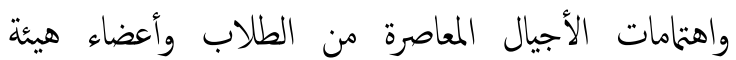

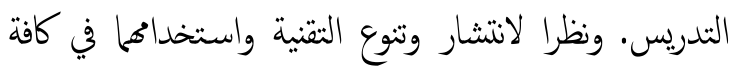

1، ما أثر اختلاف مجال التخصص الأكاديي بين أعضاء

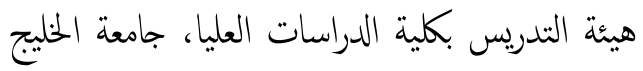
العربي على نمط التدريس المفضل لديهه؟

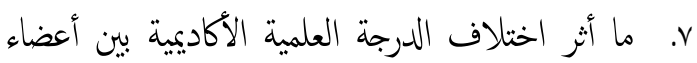

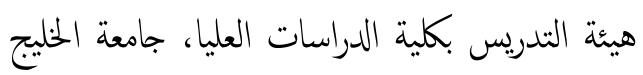
العربي على نمط التدريس المفضل لديهه؟ 1. ما أثر اختلاف سنوات الخبرة بين أعضاء هيئة

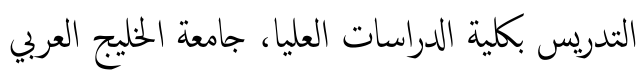
على نمط التدريس المفضل لديهم؟

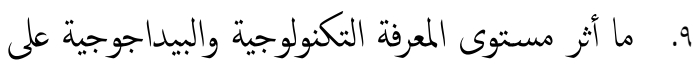

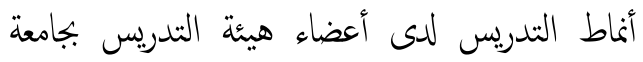
الخنيج العربي؟

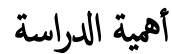

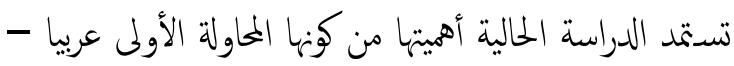

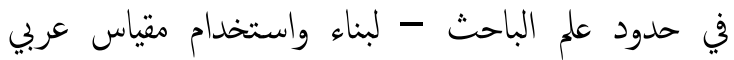

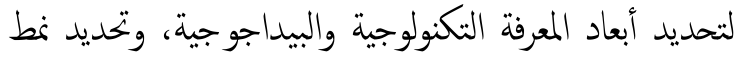
التدريس المفضل لدى أعضاء هيئة الندريس بالتعليم الجامعي بالتطبيق على جامعة الخليج العربي.كما تستمد الدراسة أهمينها من كونها تسعى لرصد وتصنيف الممارسات البيداجوجية

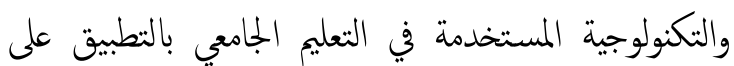

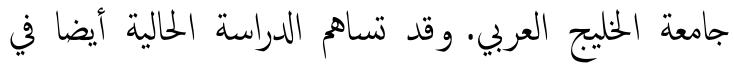

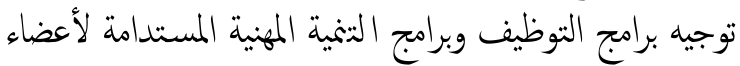

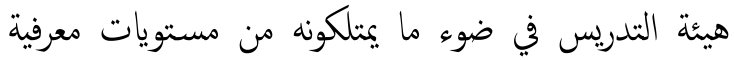

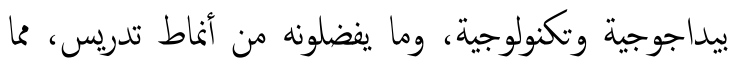

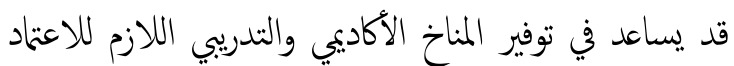

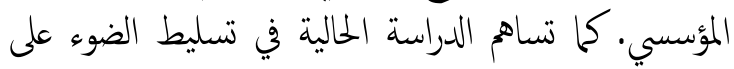

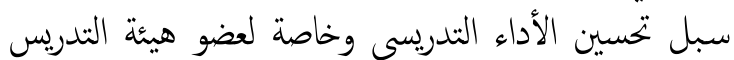
الجديد Novice Faculty من خلال وضع التوات لتوصيات اللازمة لتهيئة المناخ التدريبي اللازم لاحتضانه وتهيئنه تهيئة

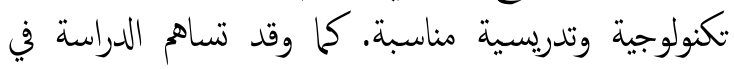

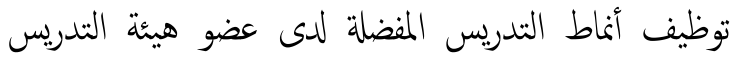

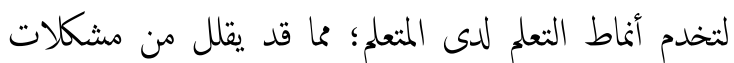
التفاعل ومشكلات إدارة الصفوف التعليمية الجامعية.

أهداف الدراسة

سعت الدراسة إلى تحقيق الأهداف التالية' 
والبيداجوجية في اكتشاف أدوار جديدة للمتعلم؛ فلم يعد

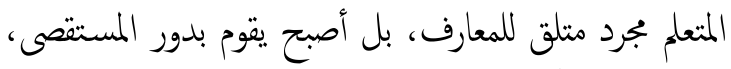

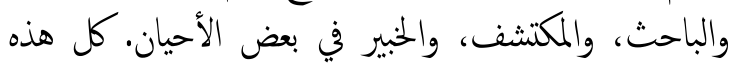

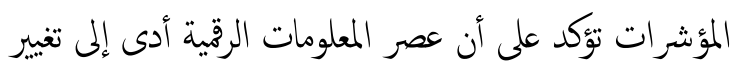

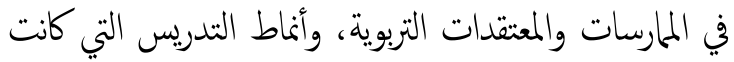

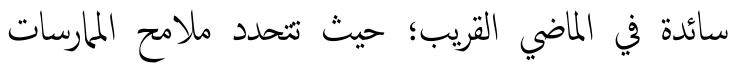

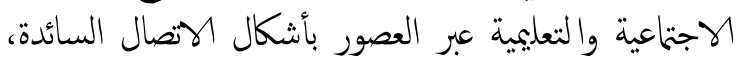

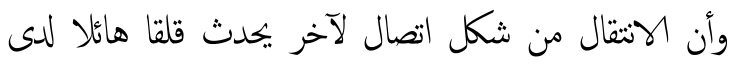

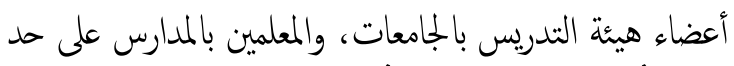
سواء (عبد العزيز، باء هيثة الثربس بالجامعات أ). وفي الآونة الحديثة، اهتمت بعض الجامعات بتنمية وتطوير

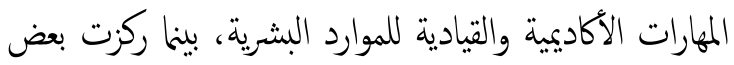

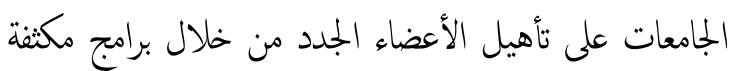

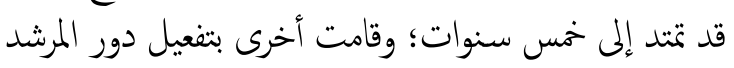
العكسي Reverse Mentoring عن طريق تعني أنسين أعضاء هيئة التدريس الأحدث والأكر كفاءة من الناحية النكنولوجية

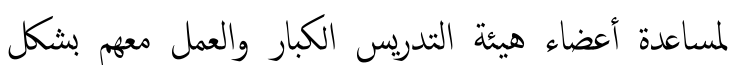

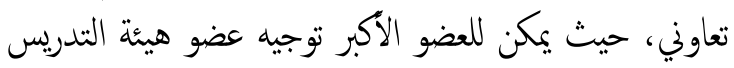

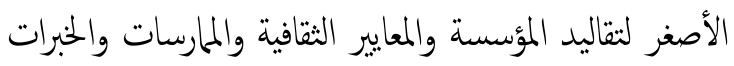

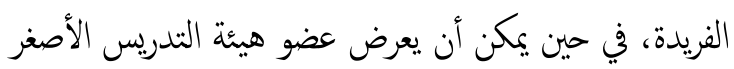

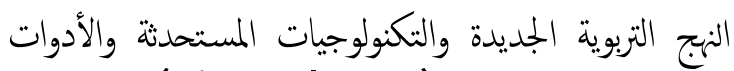
النعليمية وطرق التوصيل (Diaz et al., 2009).

أبعاد معرفة عضو هيئة التدريس

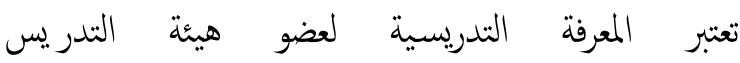
Teacher's Pedagogical Knowledge مكونات الإعداد والنمو المهني للمعلم الجامعي. وتثنوع المعرفة

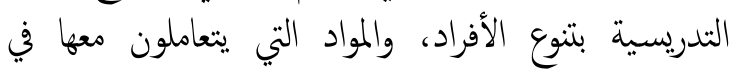

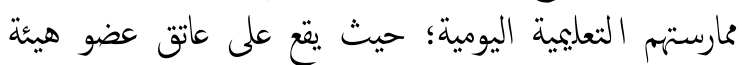

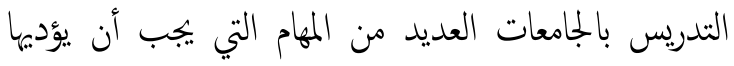

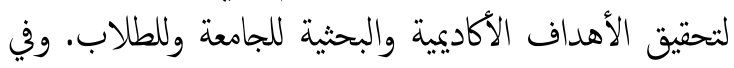

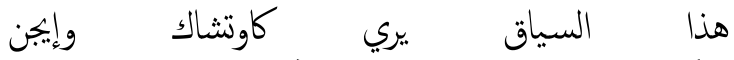
أنه ينبغي على عضو (Kauchak \& Eggen, 1998) هيئة التدريس أن يعرف المختوى الذي يعلمه (المحتوى،

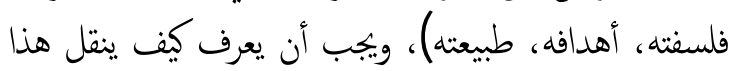

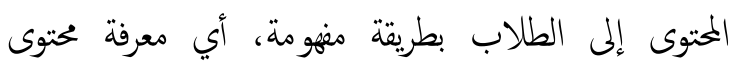

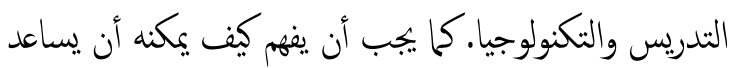

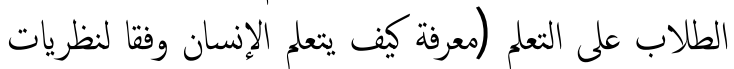

المهام التعليمية، فقد أصبح الاهتمام بالإستراتيجيات التي من

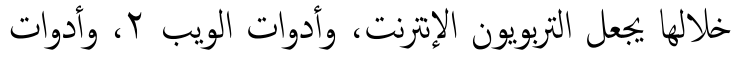

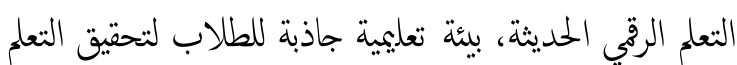

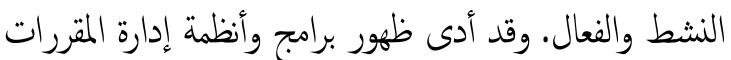

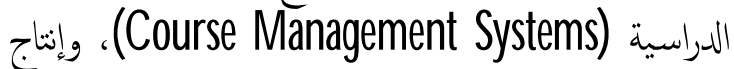
برامج وأنظمة تطبيقية لإدارة التعلم والمحتوى الإلكتروني مثل Moodle, Blackboard مكان محصور محدود الزمان والمكان إلى بيئة صفية تفاعلية مياًة للطالب في أي زمان ومكان لتغطي شريحة أكبر من الطلاب. ونتج عن التطور التكنولوجي وتطبيقات تكنولوجيا التواصل الاجتماعي وأدوات الويب ب ب تغيرا في أدوار عضو هيئة التدريس بالجامعات، فلم يعد عضو هيئة التدريس مسئولا

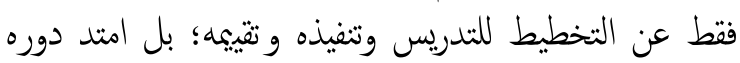

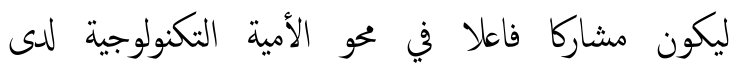

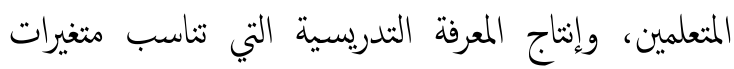

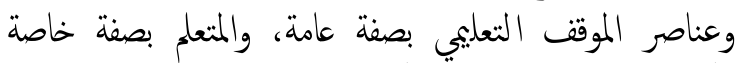

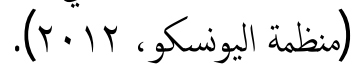

ولقد فتحت تكنولوجيا المعلومات الرقية موردا جديدا للتعليم

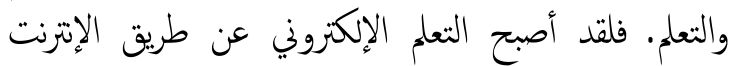

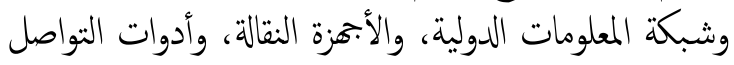

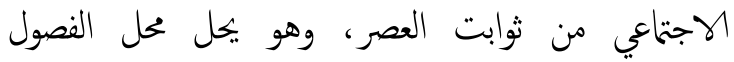

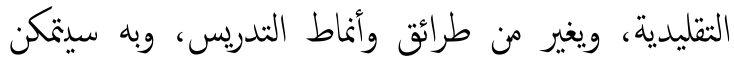

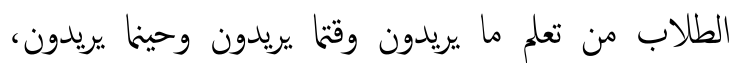

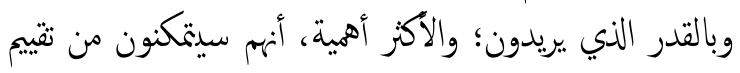

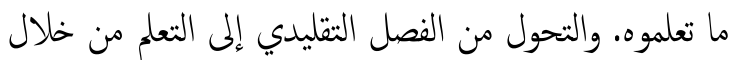

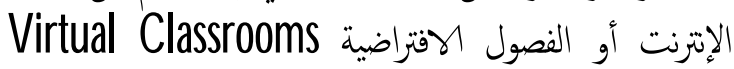
والفصول الذيكة Smart Classrooms، والفصول المقلوبة الفترن

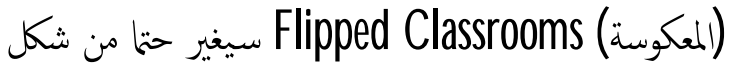

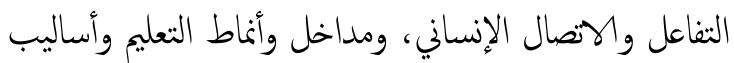
التقويم (Abdelaziz, 2013)

إن الإلمام بالمعرفة التكنولوجية والبيداجوجية معا يساهم في تغيير وتحسين ملامح لنظام التعليمي الجامعي بعناصره المختلفة.

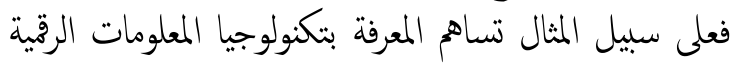
في تغيير دور عضو هيئة الندريس - كأحد عناصر النظام

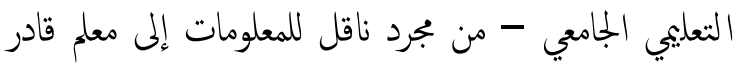

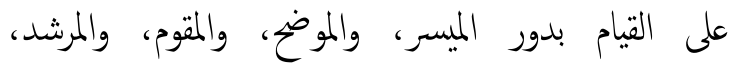
والمدرب، والقائد البناء، كما تساهم المعرفة التكنولوجية المورجة 
- المعرفة بالسياقات التعليمية، بما في ذلك خصائص الجماعات والمجتمعات والثقافات.

- - المعرفة بالغايات والأهداف والقيم التعليمية وأصولها

$$
\text { الفلسفية والناريخية. }
$$

ونتيجة لاتساع هذه المجالات فإن المدود بينها نفاذة، إذ أن فهم

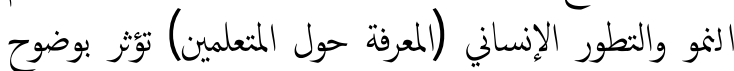

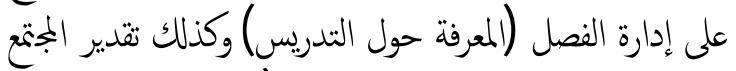

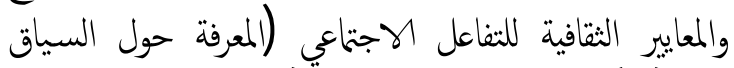
الثقافي) (عبد العزيز وقاسم ، V... r ).

هذا التصور للمعرفة والمهارات والميول التدريسية يتطابق إلى

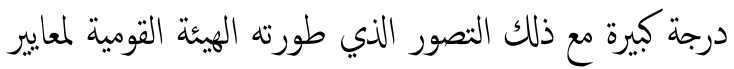

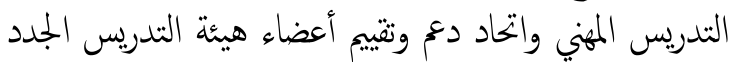
عبر الولايات National Council for Accreditation التطوير معايير of Teacher Education (NCATE) إجازة نموذجية متناغمة وواسعة حيث نظمت الهيئة القومية لمعايير التدريس المهني تطوير معاييرها حول خمسة افتراضات ونسات رئيسة، يوجد محتواها بشكل مفصل في منشورات المير الميئة

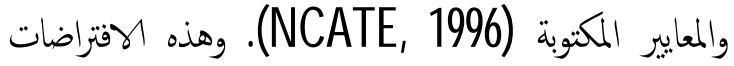

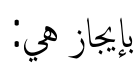

- أن يكون لدى عضو هيئة الندريس التزاما نحو الطلاب وتعلمهم' - انون

- أن يعرف عضو هيئة الندريس المواد التي يدرسها وكيف يدرس هذه المواد للطلاب.

- أن يكون عضو هيئة التدريس مسئولا عن إدارة ومتابعة تعلم الطلاب.

- أن يفكر عضو هيئة التدريس بشكل منظم في ممارساته وأن يتعلم من الخبرة.

- أن يكون عضو هيئة التدريس عضوا فعالا في

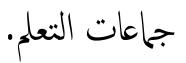
وقد وضع اتحاد تقييم ودع أعضاء هيئة التدريس الجدد عبر National Board for Professional الولايات المتحدة المتحدة Teaching Standards (NBPTS)
التعلم، وكفية تقييم التعلم)، غير أن الفهم الكلمل للعناصر

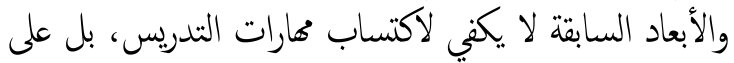

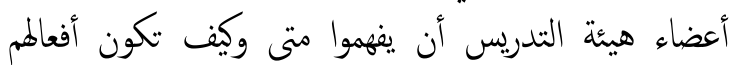

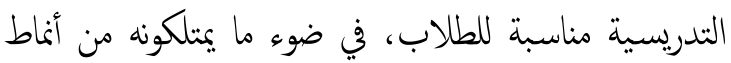
مختلفة للتعلم . واستنادا إلى ما سبق يمكن القول أن عملية اتخاذ القرارات التدريسية الفعالة تتوقف على معرفة وممارسات أعضاء هيئة

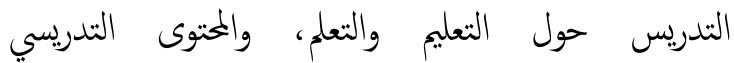
والتكنولوجي، والمادة الدراسية، وأنماط تقديمها أو توصيلها

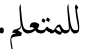
(1) المعرفة البيداجوجية لأعضاء هيئة التدريس' إن ترتببات

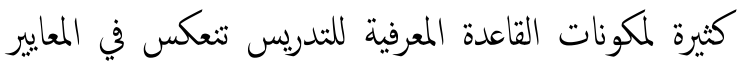
المهنية حديثة التطوير، والبحوث وتطبيقات إعداد المعلم

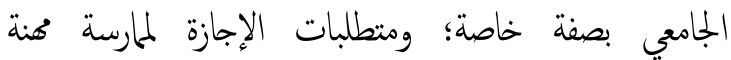

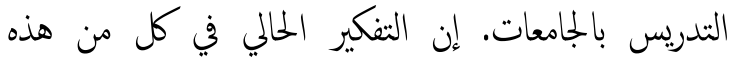

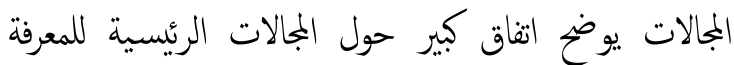
المطلوبة كأساس للتدريس المهني الملائم لعضو هيئة التدريس. وقد بدأت المناقثات حول القاعدة المعرفية للتدريس بالتأكيد

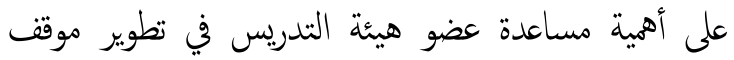

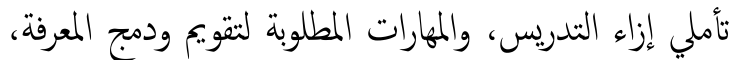

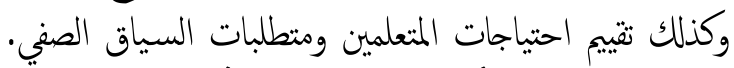
ويصنف شولمان (Shulman, 1986) عناصر المعرفة المينة التدريسية لعضو هيئة التدريس إلى:

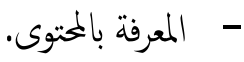

- المعرفة الندريسية، بما في ذلك مبادئ واستراتيجيات

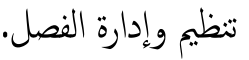
- المعرفة بالمنهج، بما في ذلك المواد والبرامج والمقررات الدراسية. - المعرفة بالمحتوى التدريسي، وهو مزيج من المحتوى

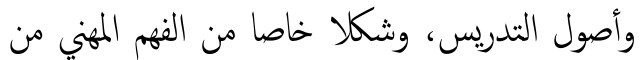

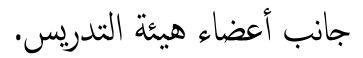
- 
للمؤسسات التي ترغب في تحديد أبعاد المعرفة التكنولوجية اللازمة لدمج التكنولوجيا في التعليم والتدريس الجامعي. ثمة أداة لتحديد المعرفة التكنولوجية لأعضاء هيئة التدريس

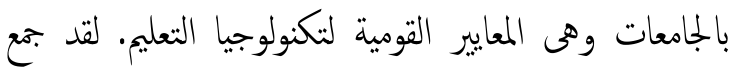

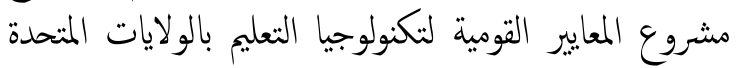

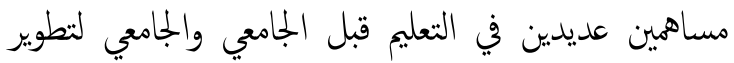

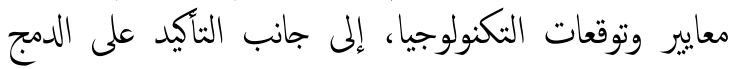

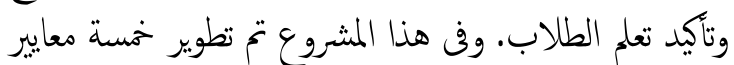

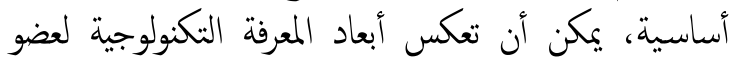

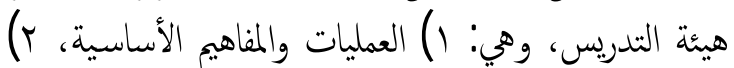

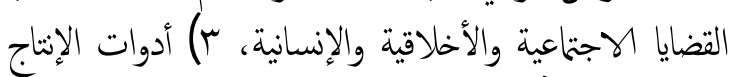

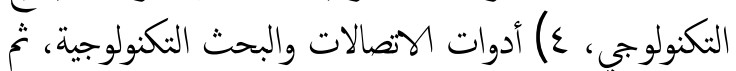

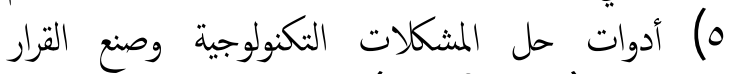
التكنولوجي (NETS, 2009) وقد أجرى هوفر (H ofer, 2003) دراسة استهدفت معرفة

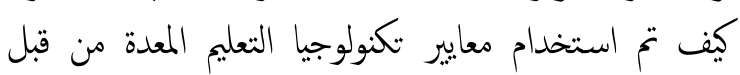

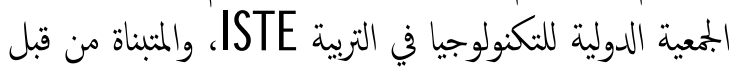

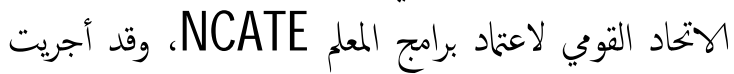

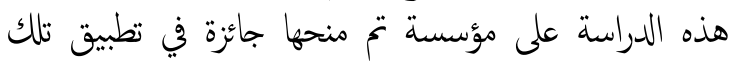

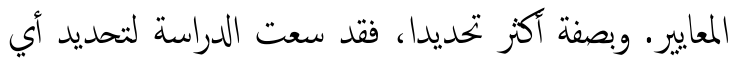

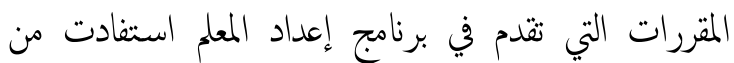
تطبيق تلك المعايير، وكيف تم تدريس المفاهيم والتطبيقات

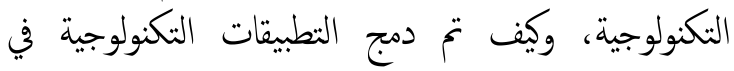
التطبيقات التربوية، وما المعوقات والحوافز وعوامل الدعز التي لتئي

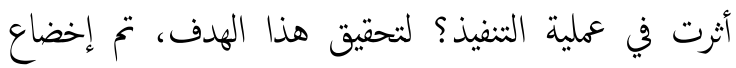

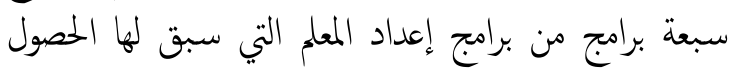

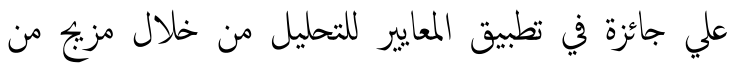

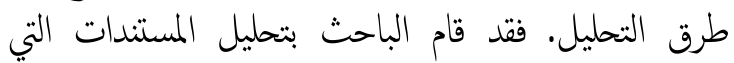

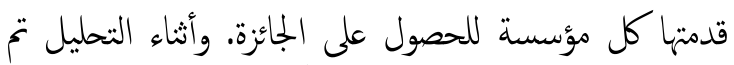

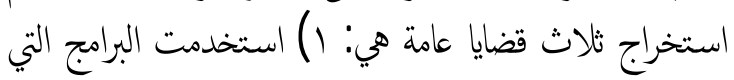

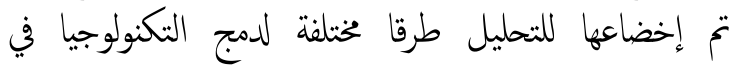
المقررات التي تقدم من خلالها، يشترك في ذلك المقات المقررات الإجبارية والاختيارية؛ r) أن مقرر تكنولوجيا النعليم لا يركز

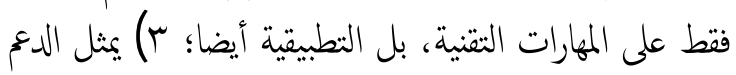
المؤسسي دورا حيويا في تطبيق المعايير.

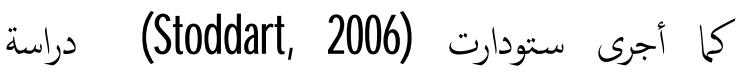
استهدفت تحديد مدى استجابة المؤسسات التعليمية
الأداء لإجازة أعضاء هيئة الندريس الذين يتفقون مع معايير

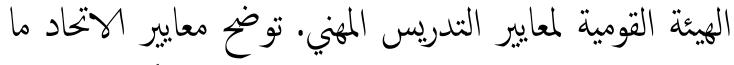

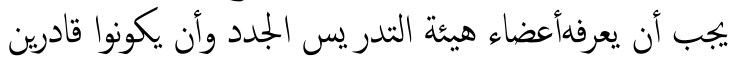

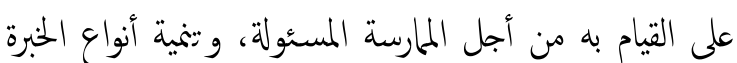
الأعمق التي تمكن من المارسة البارعة (NBPTS, 1993).

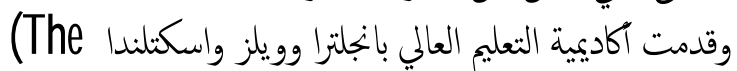
إطار ، Higher Education Academy, 2003) بالمعايير المهنية لتدعيم التدريس والتعلم الجامعي بمؤسسات

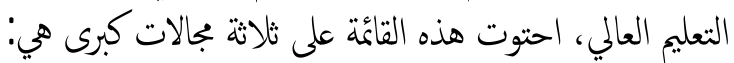

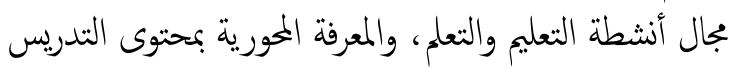

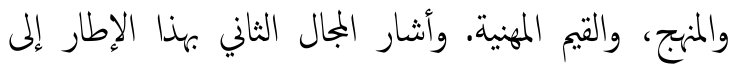

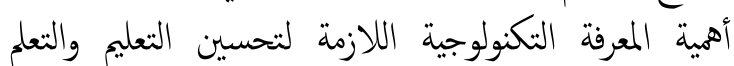
الجامعي'

\section{الم المعرفة التكنولوجية لأعضاء هيئة التدريس' (r)}

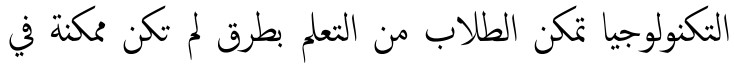

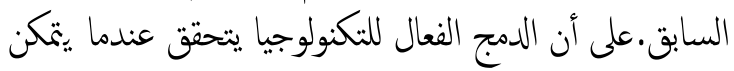

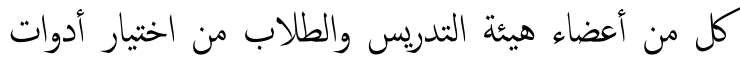

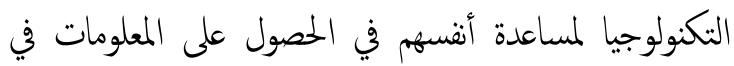

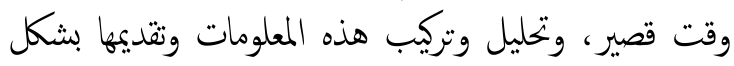

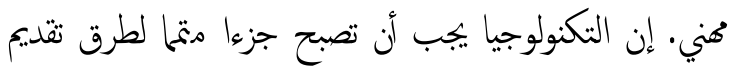
وتقييم المنهاج الدراسي بالجامعات.

وفي هذا السياق قدمت الجمعية الدولية لتكنولوجيا التعليم International Society for Technology in Education (ISTE)

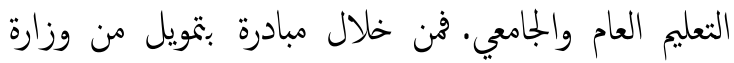

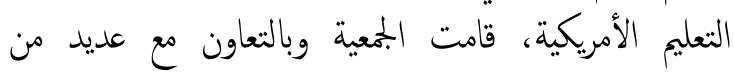

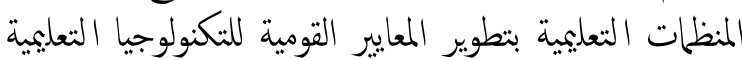

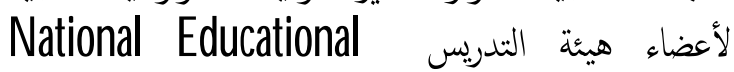
مechnology Standards (NETS)

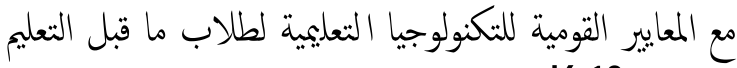

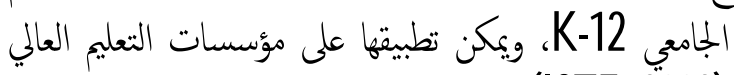

(ISTE, 2009)

وإلى جانب ذلك فإن وثيقة المعايير القومية للتكنولوجيا

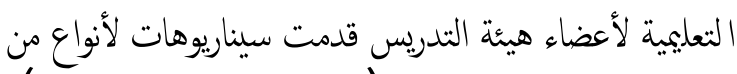

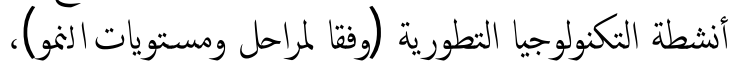

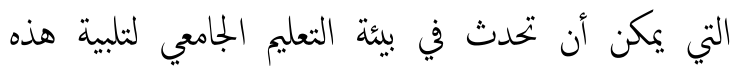

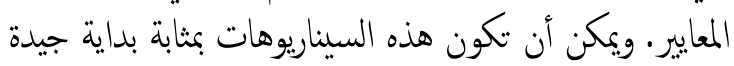


التدريس سيصبح أعضاء هيئة التدريس أكنر استعدادا

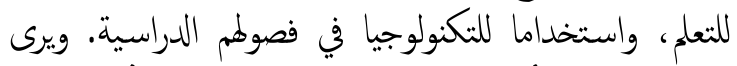

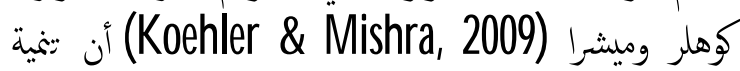
المعرفة بالمحتوى وأصول التدريس والتكنولوجيا لدى أعضاء هيئة التدريس أمر حاسم من أجل تدريس فعال باستخدام التكنولوجيا؛ ويوافقهم شين وآخرون (Shin et al., 2009) بأن إدراك أعضاء هيئة الندريس للمعرفة بالمحتوى وأصول

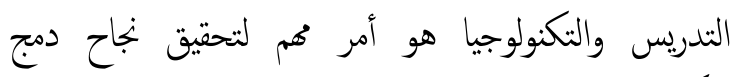
التكنولوجيا بالتعليم الجامعي. - النيا. ناقش كوهلر وميشرا (Koehler \& Mishra, 2009) المعرفة بالمحتوى وأصول التدريس والتكنولوجيا كإطار لمعرفة عضو هيئة التدريس عند دمج التكنولوجيا بالتعليم العالي، وهذا الإطار مبني على فكر شولمان المعرفة بالمحتوى

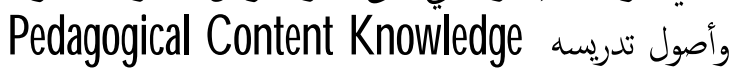

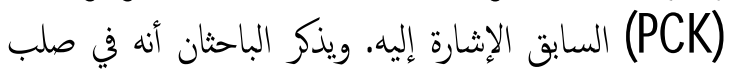

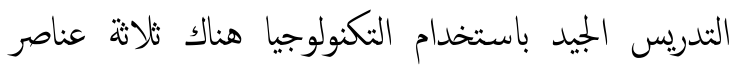

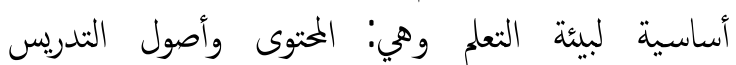

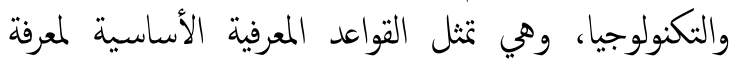

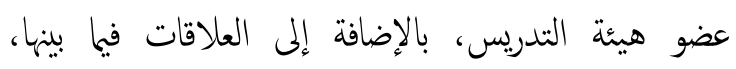

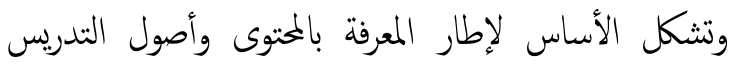

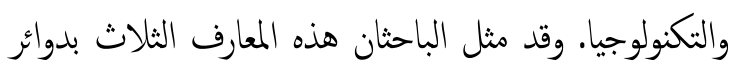

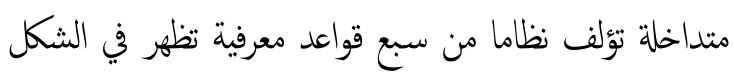
التالي.

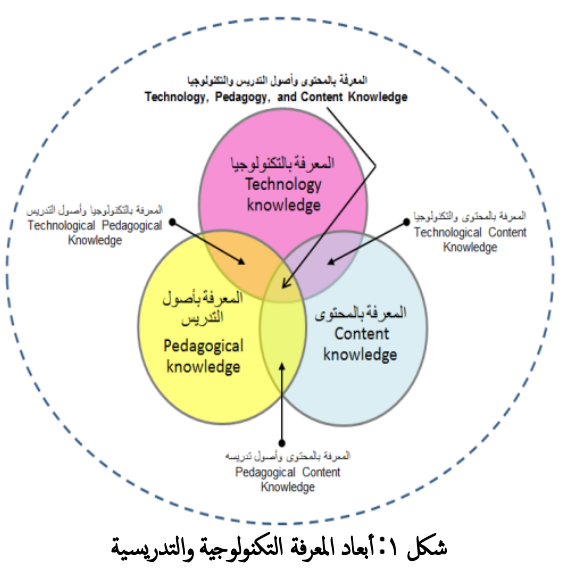

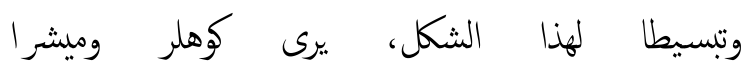
(Koehler \& M ishra, 2009)

- المعرفة بالمتوى Content Knowledge: معرفة المعلم للمادة التي يفترض تعليمها أو تعلمها.
للتوجحات الحديثة في النعليم و تتمثل هذه التوبحات في: 1 )

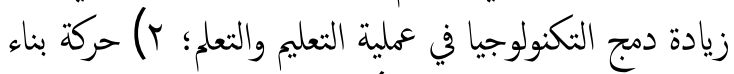

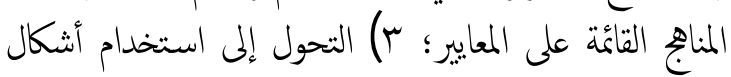

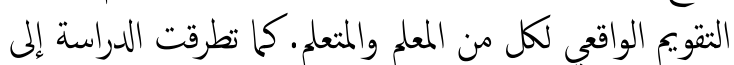

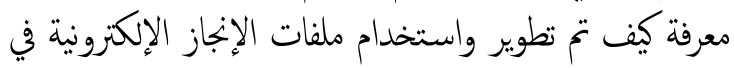

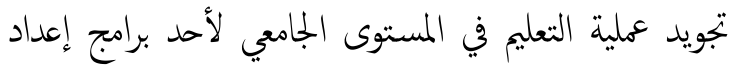

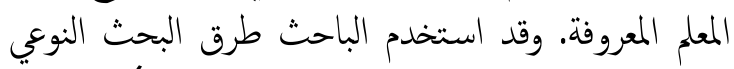

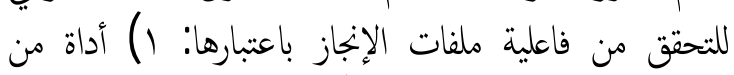

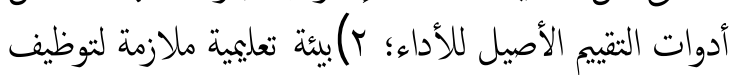

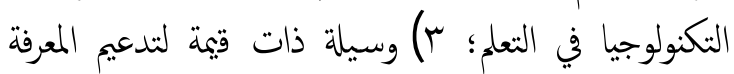

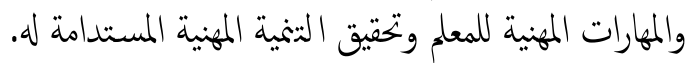
أبعاد المعرفة بالمحتوى التكنولوجي والبيداجوجي لعضو هيئة

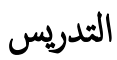

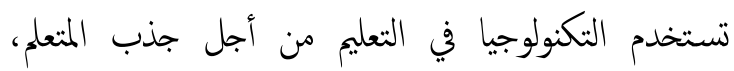

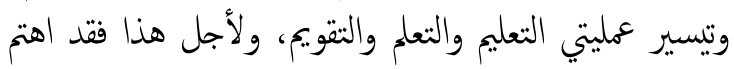

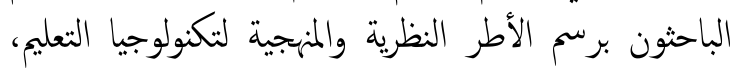

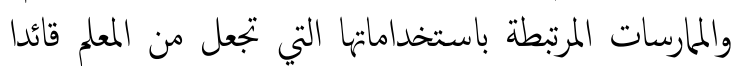
متمكنا من استثمار الإمكانات التكنولوجية في إنتاج أفضل الماتل الماتل المخرجات التعليمية، وأثمرت هذه الأبحاث عن منات مفهوم المعرفة بالمتوى وأصول التدريس والتكنولوجي TPCK وهو اختصار Technological Pedagogical Content المطار Knowledge Technological Pedagogical Content and Knowledge والتكنولوجيا هو إطار نظري رسمه كلام كلا من ميشرا

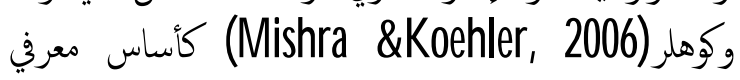

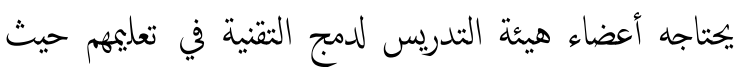

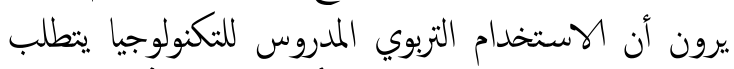

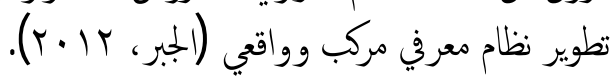
ولقد أجرى الكثير من المهتمين بالتعليم والتعلم دراسات متنوعة

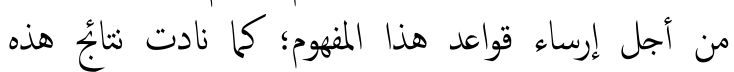

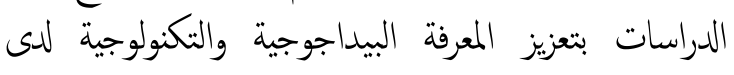
أعضاء هيئة التدريس في التعليم العالي ولجميع التخصصات؛ أنه (Kenney, Banerjee, \& Newcombe, 2010) عند توضيح العلاقات بين الختوى والتكنولوجيا وأصول 
بالإضافة إلى إدراك المعارف السابقة للطلاب والنظريات

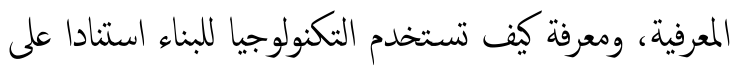

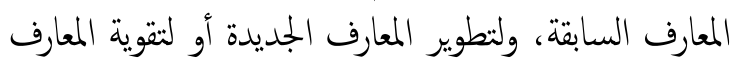

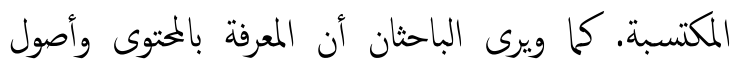

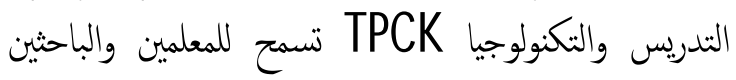
ومربي المعلمين بتغيير الطرق التي تعامل التكنولوجيا كإضافة التهائ

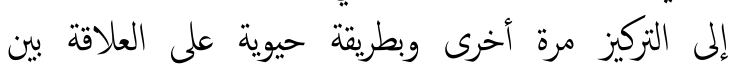

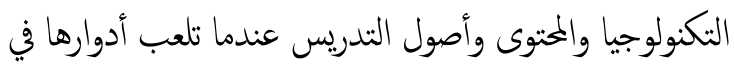

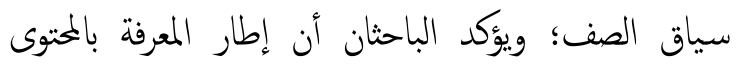

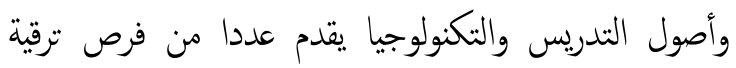
البحث في ججال إعداد عضو هيئة التدريس، والتطوير المهني له ، واستخدامه للتكنولوجيا.

TPCK إن المعرفة بالمحتوى وأصول التدريس والتكنولوجيا

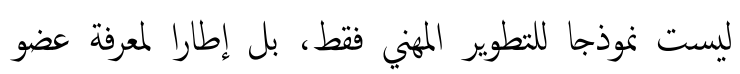

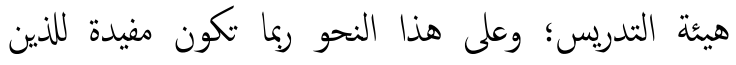

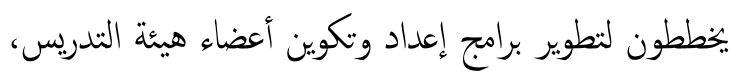

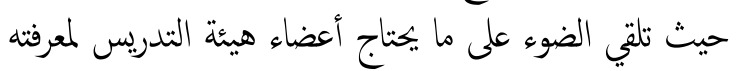

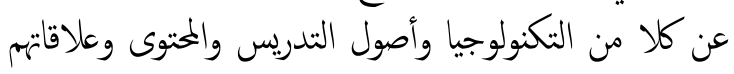

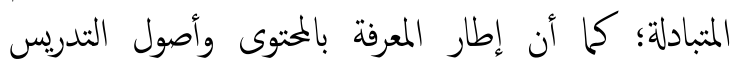

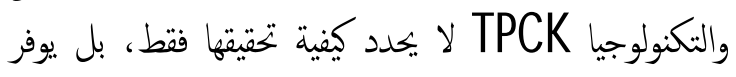

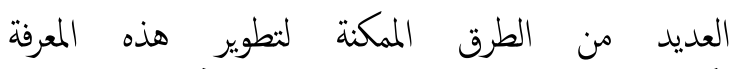
(H arris, Mishra, \& Koehler, 2009)

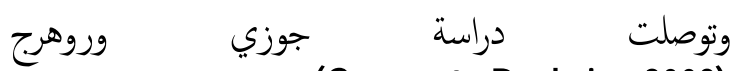
(Guzey \& Roehrig, 2009) برامج التطوير المهني باقتراحات تهدف إلى تحسين نمو المعرفة بالمحتوى وأصول الندريس والتكنولوجيا لدى معلمي العلوم، كما

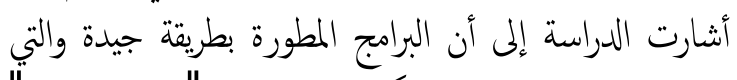

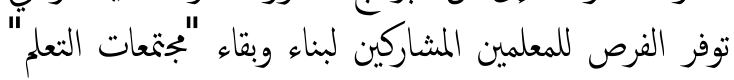

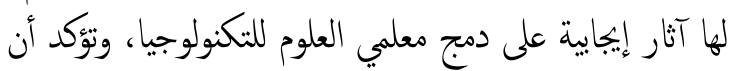

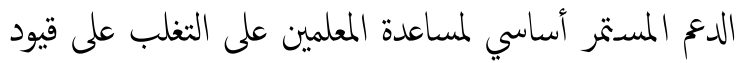

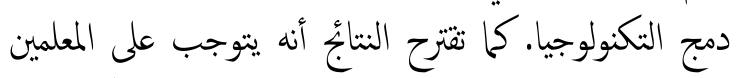

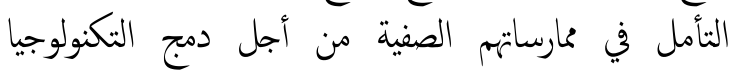

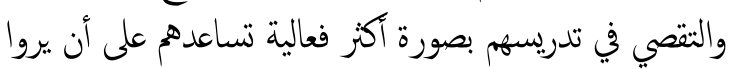

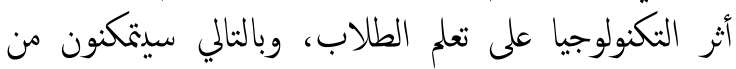

$$
\text { تعديل ممارساتهم بشكل مستمر . }
$$

أثماط التدريس' يوجد خلط شائع بين التربويين فيا يخص أثماط

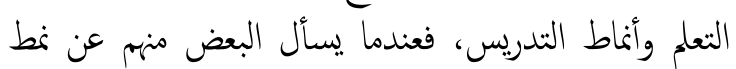

Pedagogical Knowledge العميقة بعمليات وممارسات وأساليب التعليم والتعلم. - المعرفة بالتكنولوجيا Technology Knowledge وهي المعرفة التي تمكن المعلم من إنجاز محام مختلفة

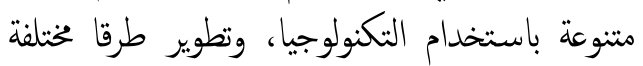
لإنجاز محمة مخطط لها.

Pedagogical Content Knowledge معرفة أصول التدريس التي يمكن تطبيقها لتدريس محتوى معين. Technological Content Knowledge فهم كيف يمكن أن يؤثر كلا من التكنولوجيا والمحتوى أحدها بالآخر.

:Technological Pedagogical Knowledge وهي فهم كيف يككن للتعليم والتعلم أن يتغير عند

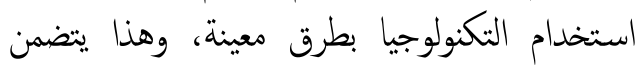

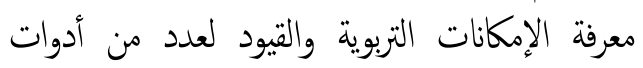
التكنولوجيا من حيث صلتها بضبط واختيار أو تطوير استراتيجيات وأساليب تدريس مناسبة.

- المعرفة بالمحتوى وأصول التدريس والتكنولوجيا Technology, Pedagogy, and Content Knowledge

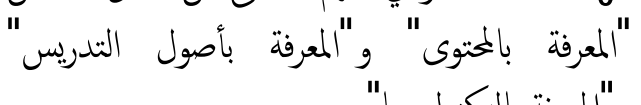
و "المعرفة بالتكنولوجيا"،

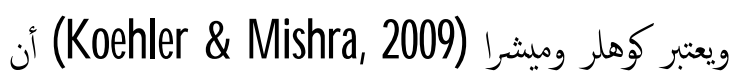

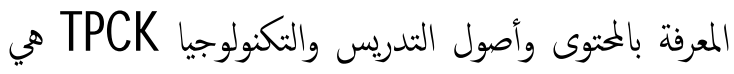

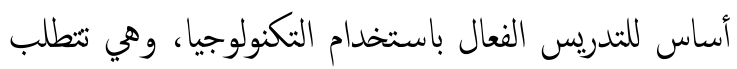

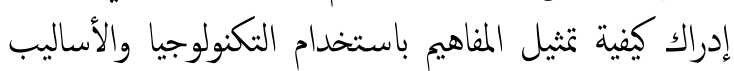

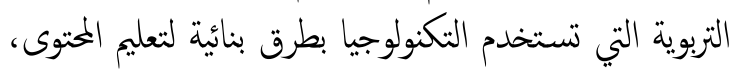

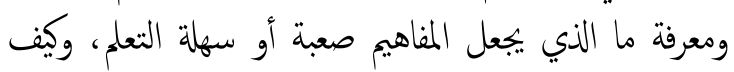

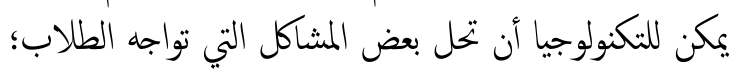




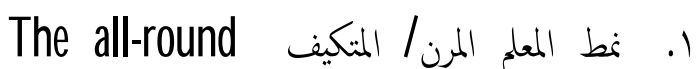
iflexible and adaptable teacher النط يوظف المعلم كثير من المهارات، وبإمكانه التدريس للطلاب الجدد والمتقدمين في المراحل التدريسية، ولديه وعي كاف بالبيئة والمناخ التعلييي الماتيل الذي يؤثر في التدريس والمتعلمين.

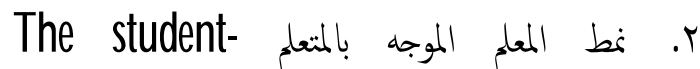
(centered, sensitive teacher النطط حول المتعلي، ويضضل الندريس للمجموعات

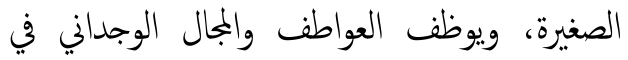
تنعيل الثدريس، كما يفضل الألعاب التعليمية والمراما فئال

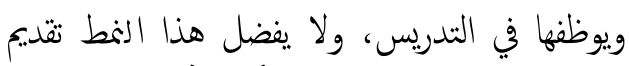
عروض تعليمية مباشرة وثابتة (خطية).

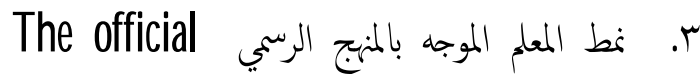
(Curriculum teacher

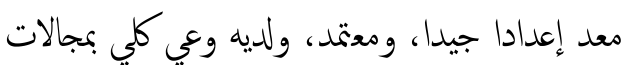
وأبعاد المنهج الرسمي، ولديه أهداف كبرى حسئ حقيقية حول المنهج المدرسي. ع. نغط المعلم الموجه بالحقائت التعليمية المستقلة الواضحة :The straight facts no nonsense teacher في هذا النط يفضل المعلم تدريس الحقائت التعليمية

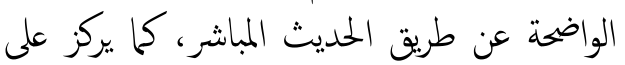

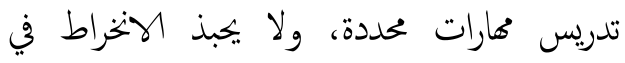
مواقف تعليمية متعددة الأهداف أو النواتج. 0. The big conference teacher يفضل المعلم تقديم محاضرات عامة لأعداد كيرة من المن المن

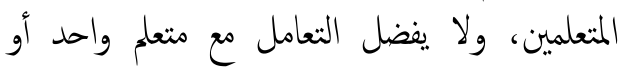
مجموعة صغيرة من المتعلمين.

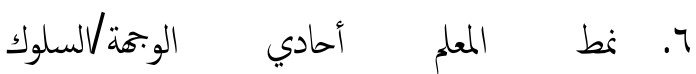
المبل

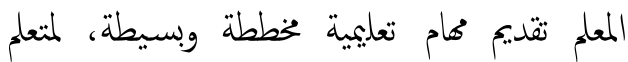

$$
\text { واحد، ولا يجبذ متابعة المتعلم في تنفيذ مهام التعلم. }
$$

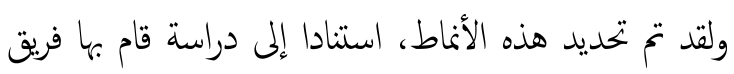

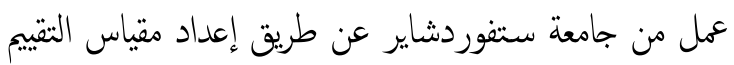

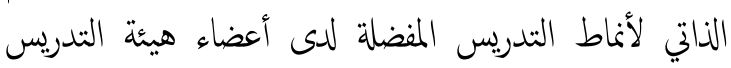

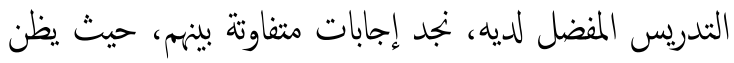

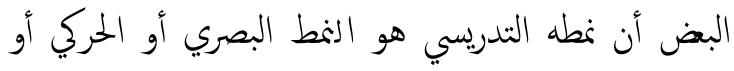

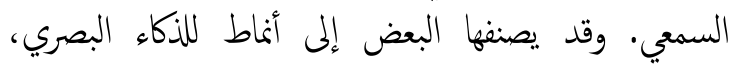

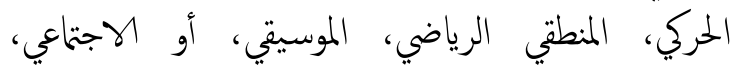

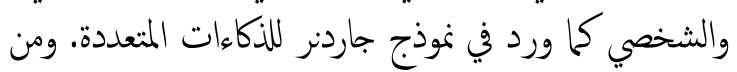

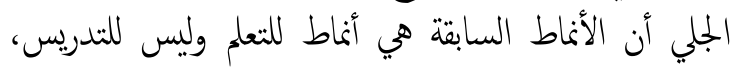

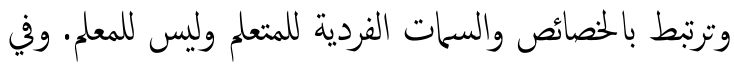

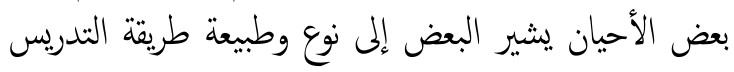

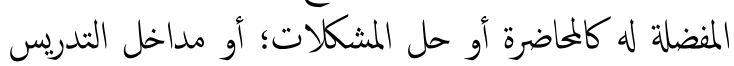

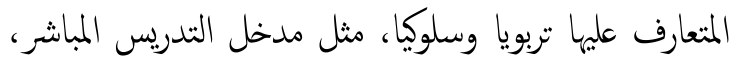

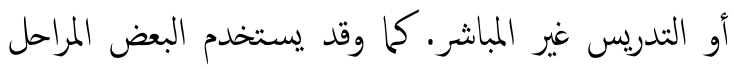

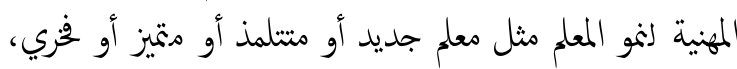

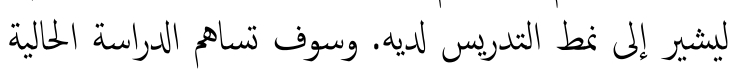
في تخنيف وتصويب هذا الخلط الشائع للتصور البديل حول الترالئ المالية نمط التدريس.

مفهوم نط التدريس' يشير الأدب التربوي والنفسي إلى أن

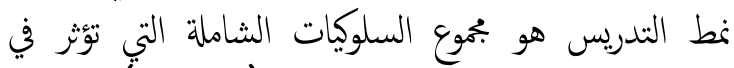

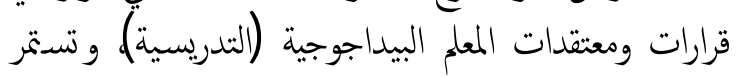

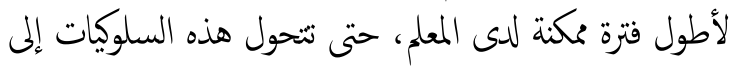

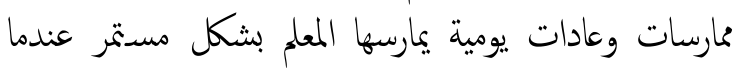

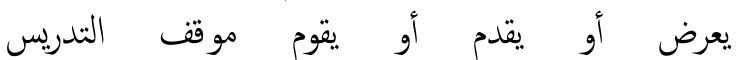
.(Mohanna, Cottrell, Wall, \& Chambers, 2007) إن قدرة عضو هيئة التدريس على فهم وتوصيف نمط التدريس

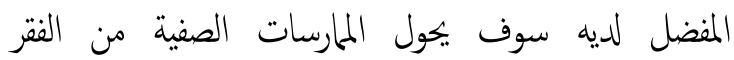
البيداجوجي "Pedagogy of poverty" إلى الثراء والتنوع النية "Pedagogy of plenty" (Tomlinson, البيداجوجيداءيديد)

.2005)

تصنيف أثماط الثدريس' يصنف الأدب التربوي أنماط

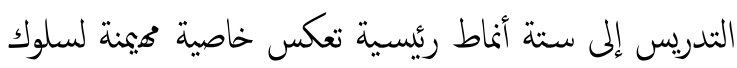

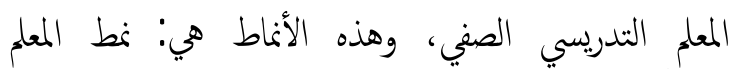

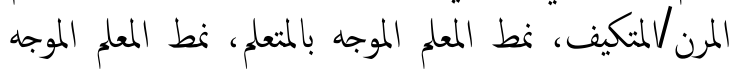

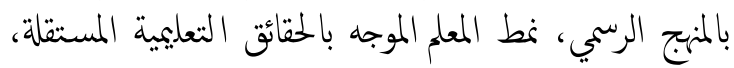

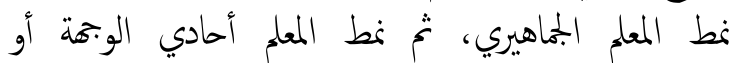

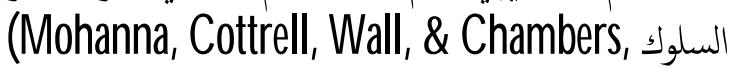
(2011، وتبسيطا على القراء والباحثين، يقدم الباحث وصفا مختصرا لكل نمط من هذه الأنماط فيا يلي' 
re-productive teaching style productive teaching style

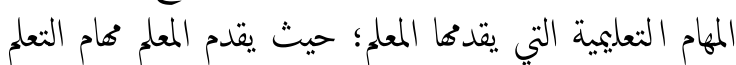

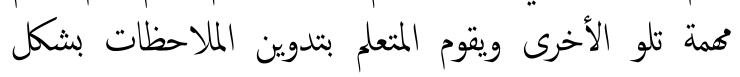

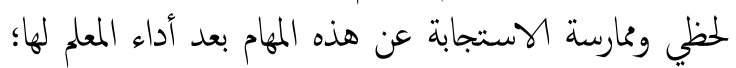

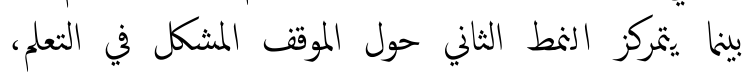

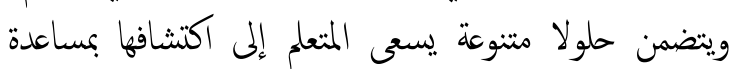
المعلم (Hein et al., 2012)

ويتأثر نط التدريس بمعتقدات ودافعية المعلم حول التدريس،

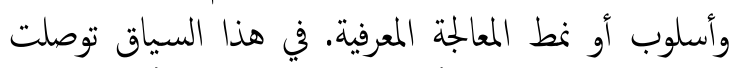

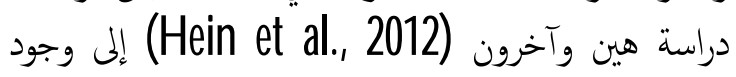

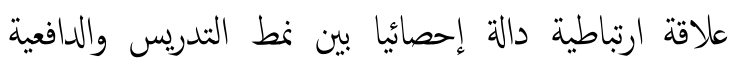

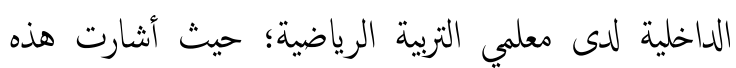

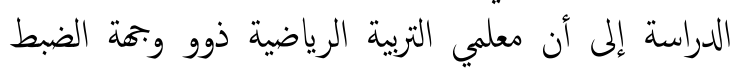

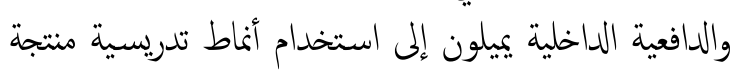

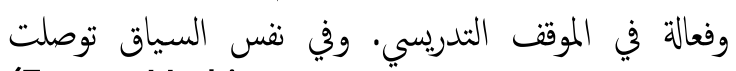
(Evans, Harkins, \& دراسة إيفان وهاركنز ويانج Young, 2008) نمط الثدريس والنمط المعرفي لدى المعلمين بالمدارس الكندية.

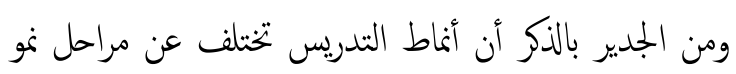

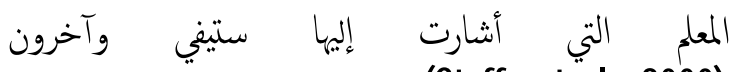

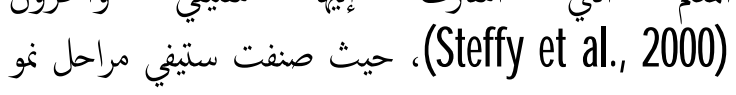
المهني للمعلم إلى ست مراحل رئسة هي: المعلم الجديد

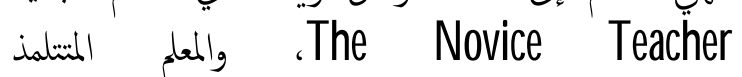
، The Apprentice Teacher The Professional Teacher The Expert Teacher The Distinguished Teacher .The Emeritus Teacher

ونستنتج مما سبق أن تحديد أنماط التدريس، وأنماط المعالجة

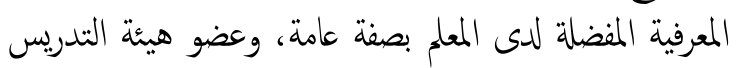

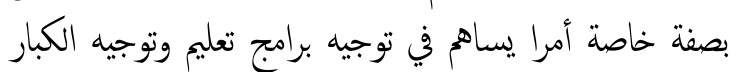

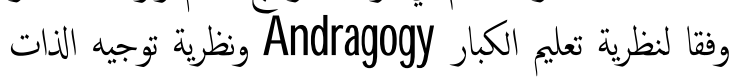
Self-determination Theory المستدامة لدى المشتغلين بكهنة التعليم على كافة مستوياتها. ومن خلال معرفة وقياس أنماط التدريس، وأبعاد المعرفة المبنة

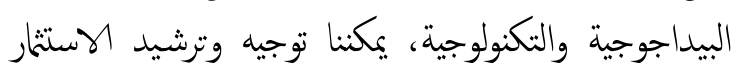

The self evaluation tool: Staffordshire هing هذا المقاس على (ع إ) فقرة تعكس الأنماط الستة للندريس

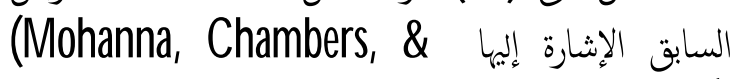
(Wall, 2007)

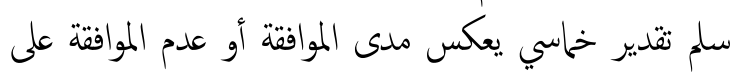

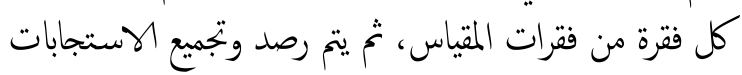

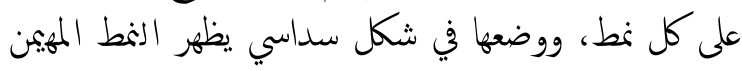

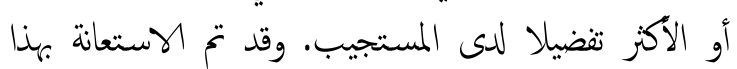

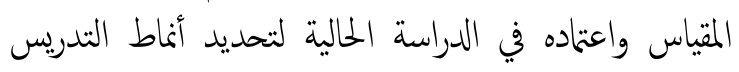

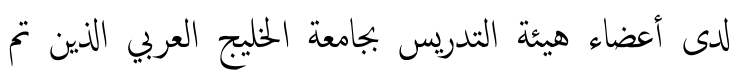

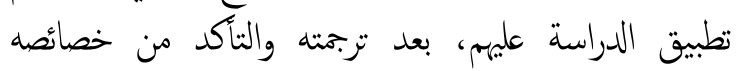
السيكومترية.

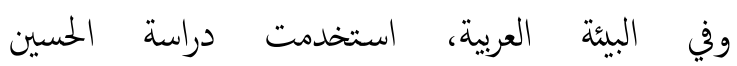
هذا المقياس لتحديد نمط التدريس (Alhussain, 2012)

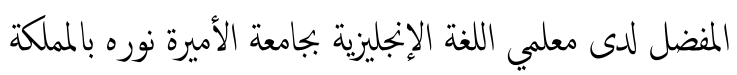

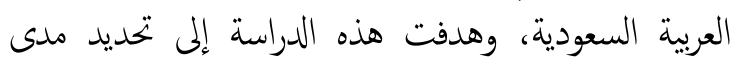

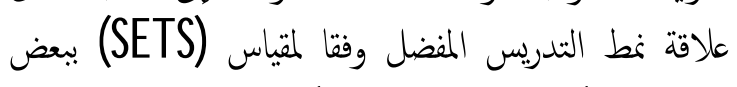

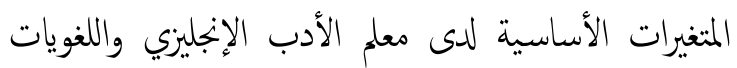

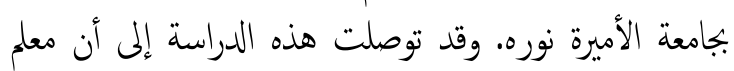

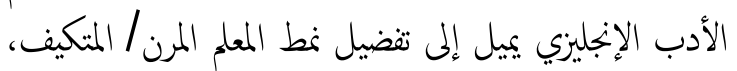

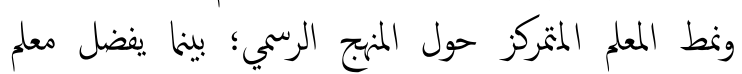

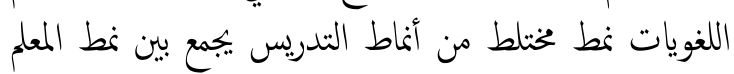
المرن والمعلم الموجه بالحقائق التعليمية، ونط المناط المعلم الجماهيري.

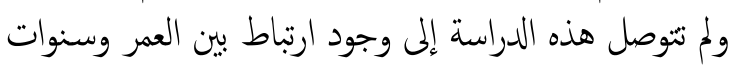

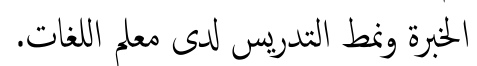

كما صنف جارفز (Jarvis, 1985) أنماط الندريس إلى ثلاثة أنماط رئسة هي: (1) النمط الشارح "a didactic style"

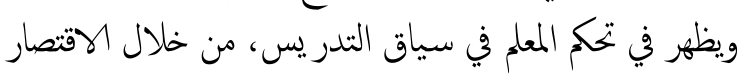

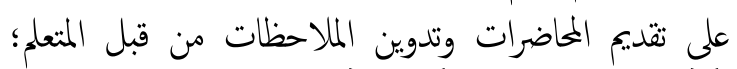

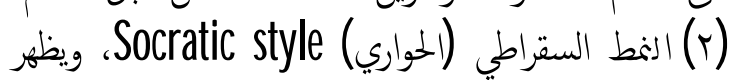

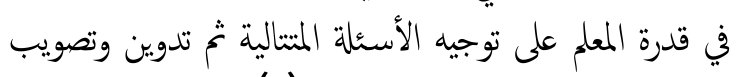

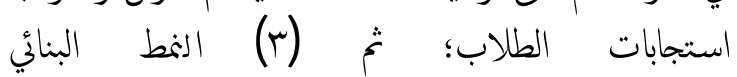
"facilitative style" وتهيئة مناخ وبيئة التعلم لجعل المتعلم مسئولا عن عملية التعلم. كما ويصنف البعض أنماط الندريس إلى نمطين أساسيين ها:

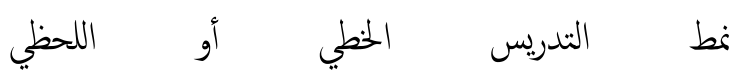


برنامج تربية الموهوبين، نظرا لسفرهم أثناء جمع البيانات.

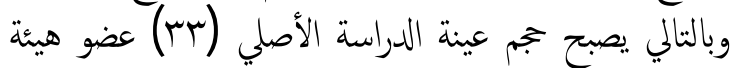

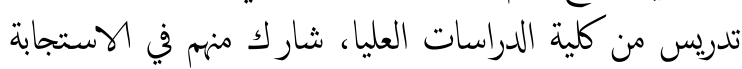

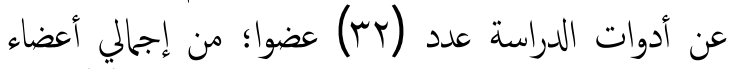

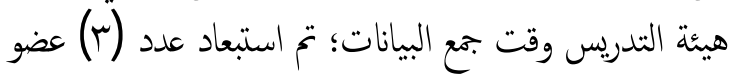

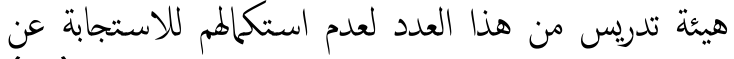

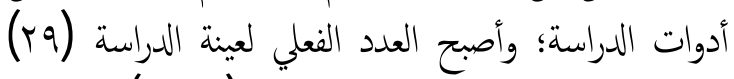

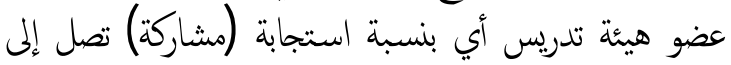
ع9\% وقد تم الاقتصار على أعضاء هيئة التدريس بكلية

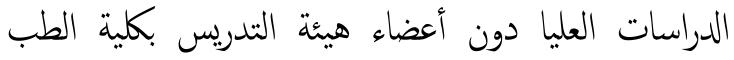

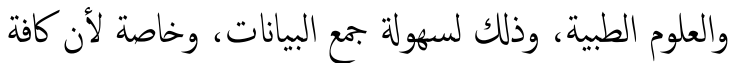

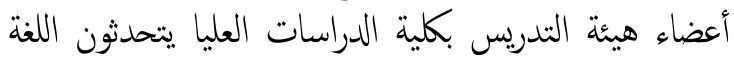

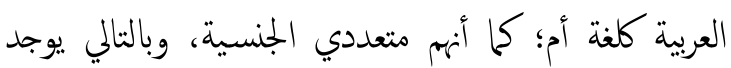

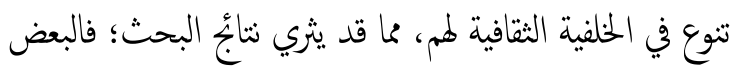

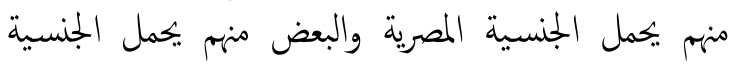

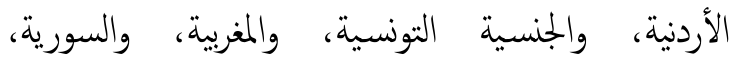

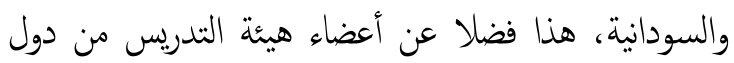
مجلس التعاون الخليجي والعراق.

وقدكان هناك تمثيل نسبي متساو إلى حد كير بين التخصص

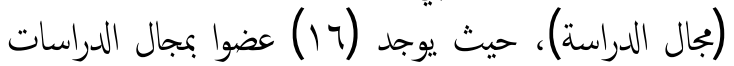

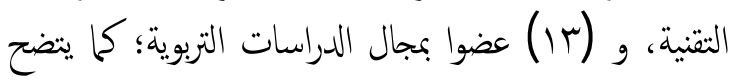

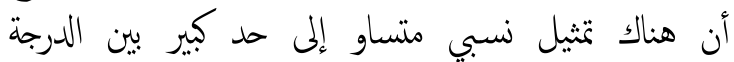

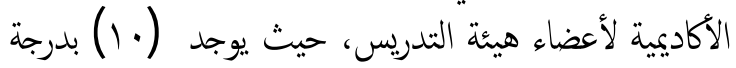

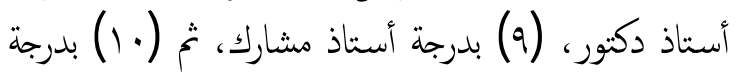

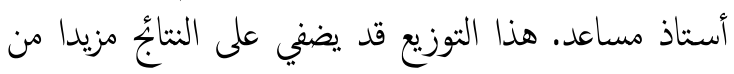

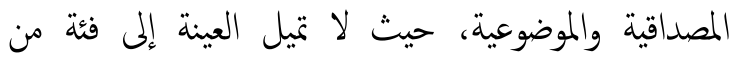

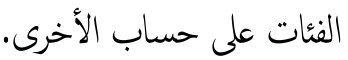

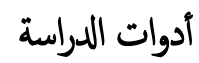

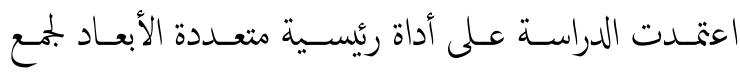
البيانات، قسمت الأداة إلى ثلاثة أجزاء، وفقا لما يلية إنئي الجزء الأول: يجتوي على Tr مفردة قصيرة، تعكس هذه

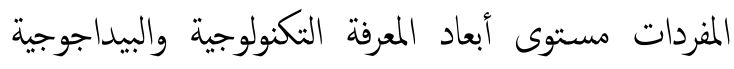

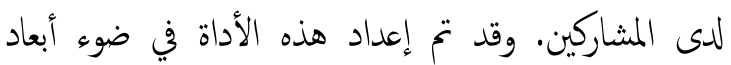
مقياس ميشرا وكوهلر (Mishra \& Koehler, 2006). وبهدف هذا المقياس إلى تحديد مستوى المعرفة والممارسة

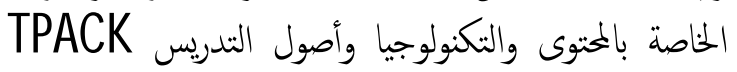

الخضصص لبرامج التنمية المهنية بالتعليم الجامي، وخاصة ما يتعلق منها بمهارات وكفايات التدريس والتكنولوجيا.

\section{مفهوم العمر البيداجوجي والتكنولوجي}

استنادا إلى ما سبق، يعر ف الباحث العمر البيداجوجي

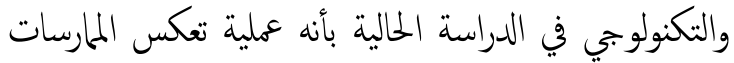

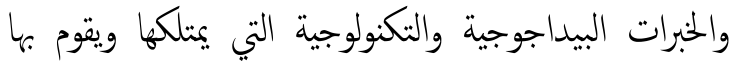

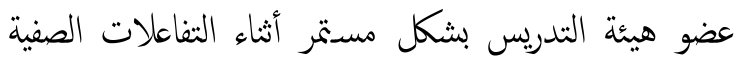

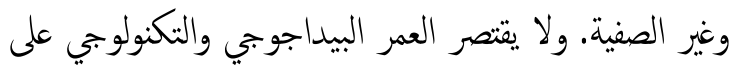

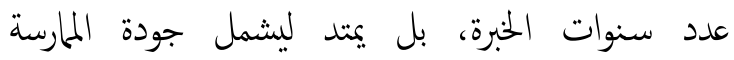
والاستمرار في تطويرها كلما تطلب الأمر ذلك.

\section{الطريقة والإجراءات}

\section{منهج الدراسة}

انتهجت الدراسة الحالية منهج البحث الوصفي التحليلي القائم

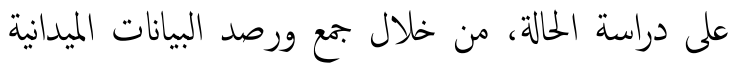
اللازمة للتحقق من صحة فرضيات الدراسة ومن ثم الإجابة عن السؤال الرئيس والأسئلة الفرعية للدراسة.

\section{مجتع الدراسة}

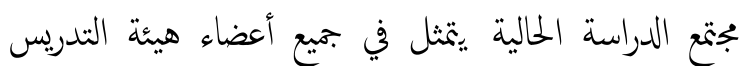

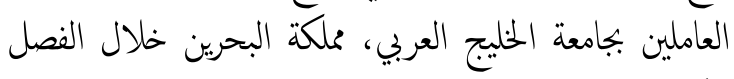

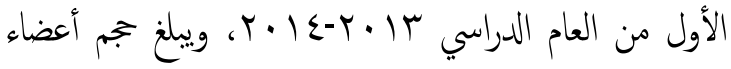

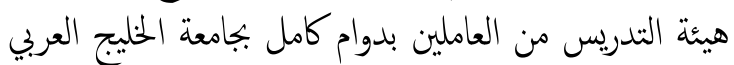

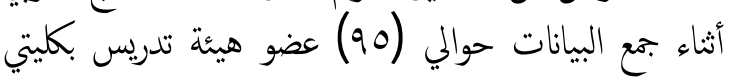

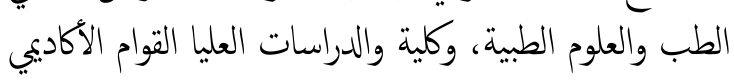

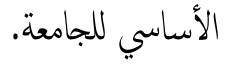

عينة الدراسة

تمثلت عينة الدراسة الحالية (الحالة الدراسية) في كافة أعضاء

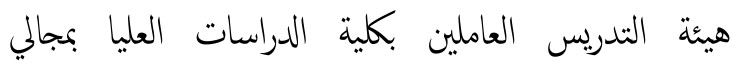

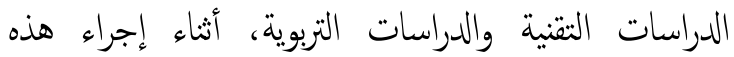

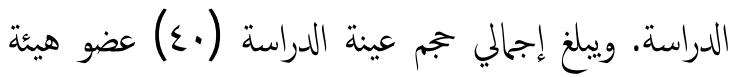
تدريس من ذوي الدوام الكلامل بكلية الدراسات العليا، تح

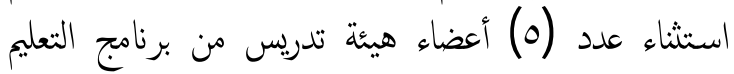

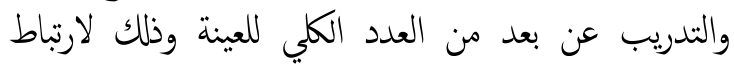
تخصصم الأكاديمي بموضوع الدراسة الحالية، وعضو هيئة

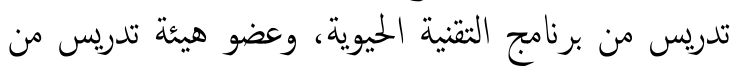




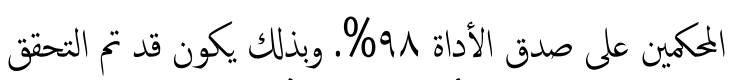
من الصدق الظاهري (صدق المكمين) لأداة البحث الرئسية. ثبات الأداة

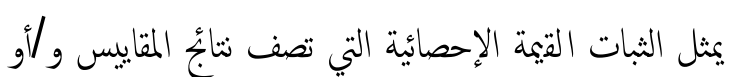

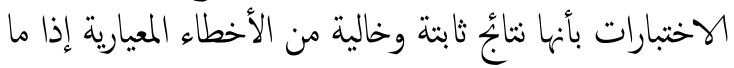

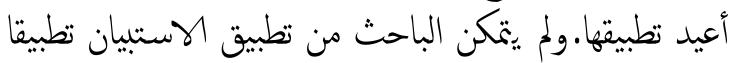

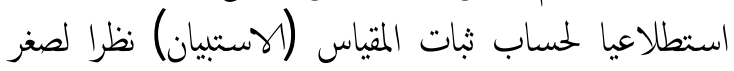

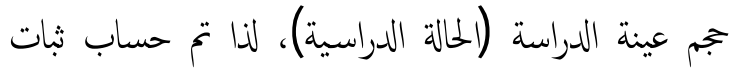

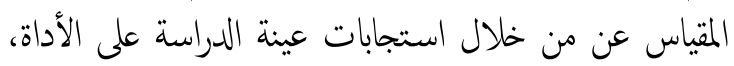

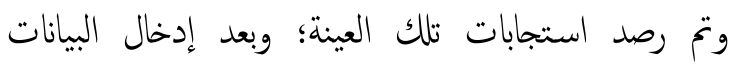

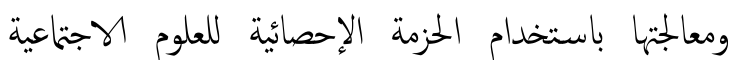
SPSS Cornbach's Alpha

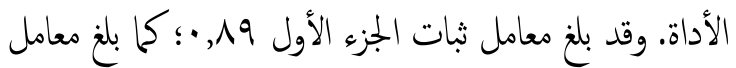

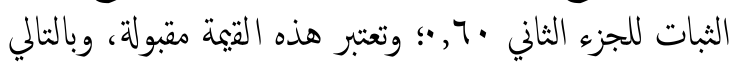

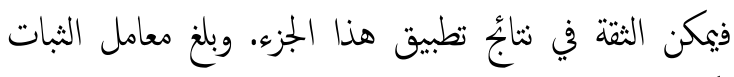
الكلي للمقياس عی, "، وتعد هذه القيمة مرتفعة، وخاصة إذا تح

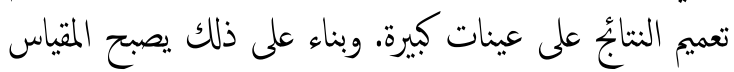

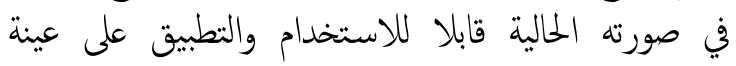

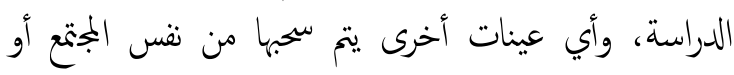

$$
\text { مجتمعات أخرى مشابهة. }
$$

تحليل البيانات

تم تنظيم البيانات المجمعة من الاستبيان في جـداول إلكنرونيـة

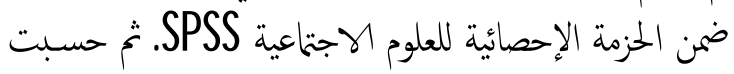

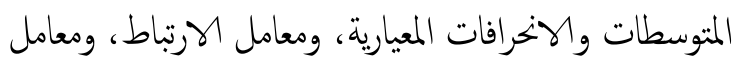

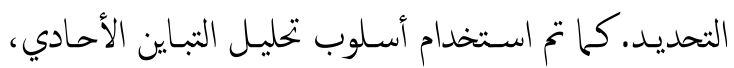

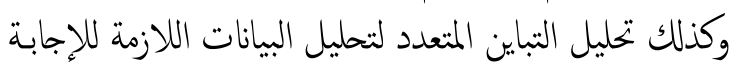
عن بعض أسئلة البحث، والتحقق من صحة فرضياته.

محددات المراسة

قبل الخوض في عرض وتحليل ننائُ هذه الدراسة، فمن الجدير بالذكر الإثارة إلى أن الدراسة ثقتصر على المحددات التالية.

- - يقتصر تعميم نتاجُ الدراسة على أعضاء هيئة الندريس

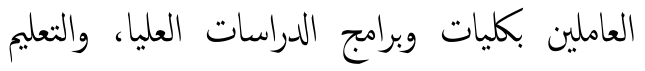

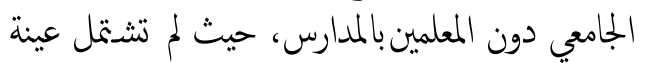
الدراسة أي فئة من المعلمين بالتعليم قبل الجامعي.
السابق الإنشارة إليه؛ وصم المقياس على طريقة ليكرت

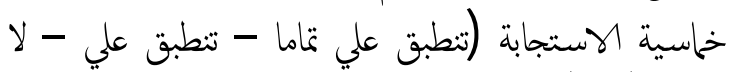

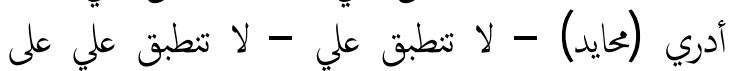

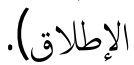

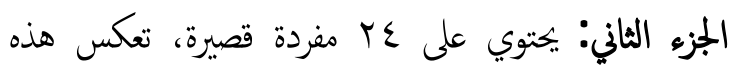

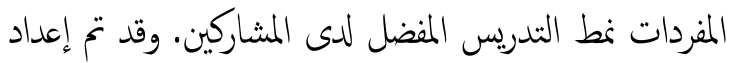

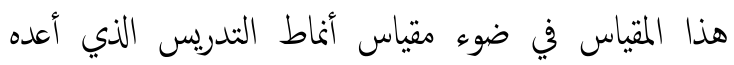

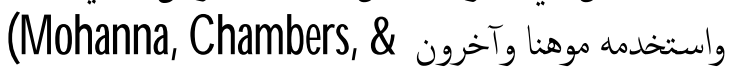
The self بجامعة ستثورد شايرن Wall, 2007) evaluation tool: Staffordshire Evaluation of الني عرضت أبعاده في Teaching Styles (SETS) الإطار النظري للدراسة الحالية. وقد تم ترجة هذا المقياس إلى الى

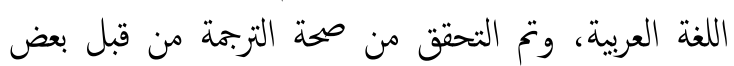
الاختصاصيين في اللغة الإنجليزية من الناطقين باللغة العربية

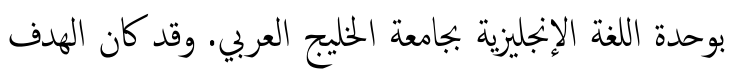

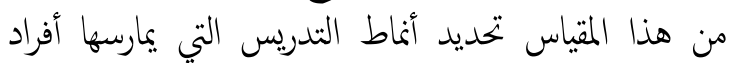

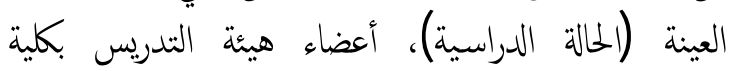
الدراسات العليا - جامعة الخليج العربي. الجزء الثالث' احتوى الجزء الثالث مـ الأداة على مفردات

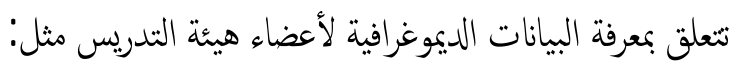

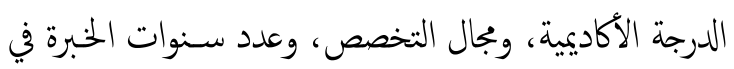

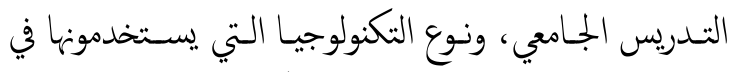

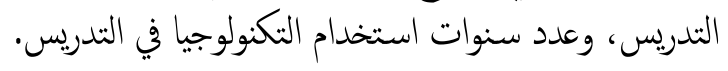

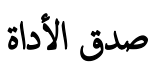

التتحقق من صدق الاستبيان تح عرضه في صورته المبدئية

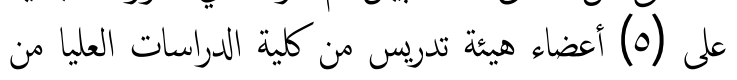

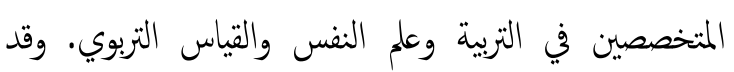
سئل السادة المكمون عن مدى مناسبة موضوع الأداة

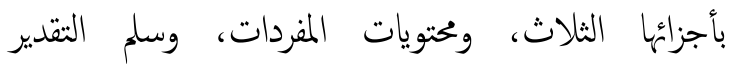

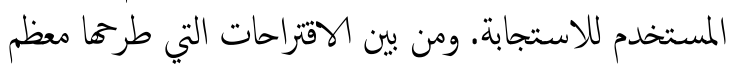

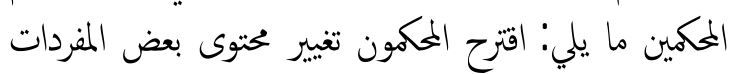

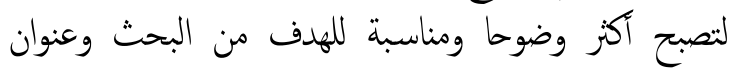
الاستبيان الجديد، وقد تم تعديل محتوى المفردات التي أشاروا

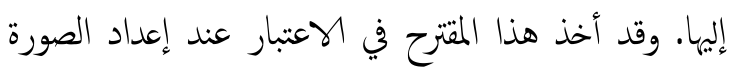

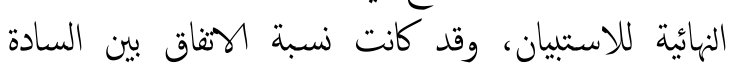


CK يككن رسم مدى ميل استجابة أعضاء هيئة التدريس بكلية

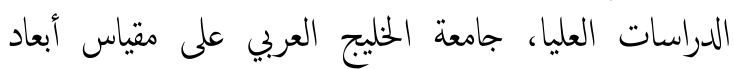

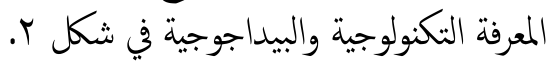

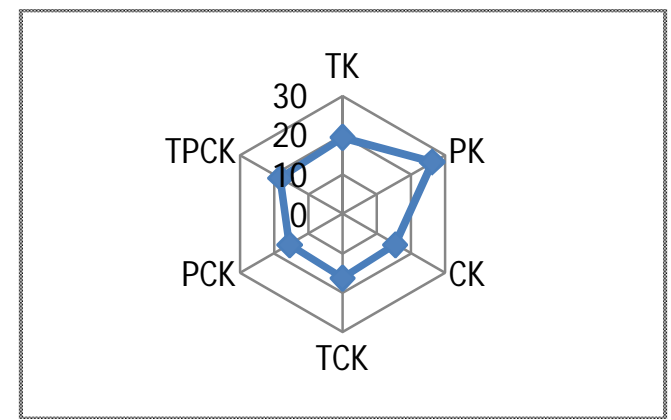

شكل ri مدى ميل استجابة أعضاء هيئة التدريس على مقياس المعرفة التكولوجية والبيداجوجية يتضح من شكل r أن أعضاء هيئة التدريس بكلية الدراسات

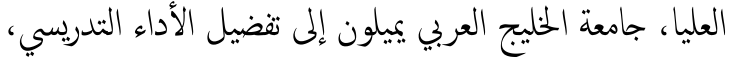

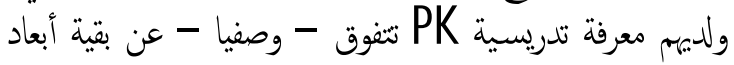

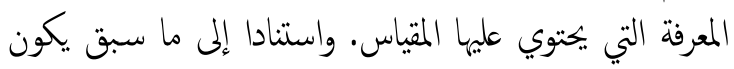
قد تم الإجابة عن السؤال الأول من أسئة الدراسة. ثانيا: الإجابة عن السؤال الثاني: ينص السؤال الثاني في الدراسة

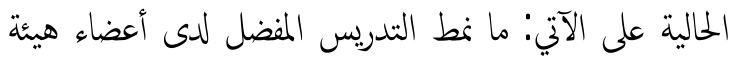

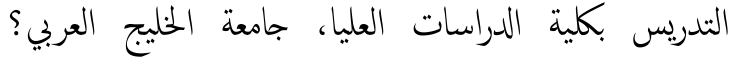

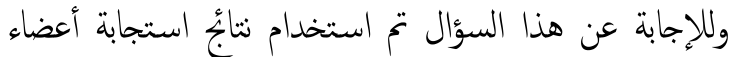

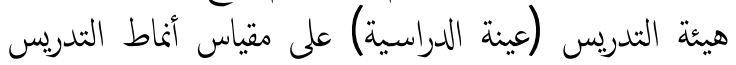
(SETS) المخصصة لكل نطط من الأنماط الستة بالمقياسن: نمط المعلم المرن

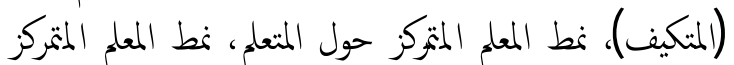

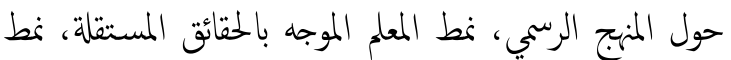

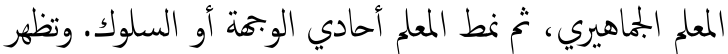

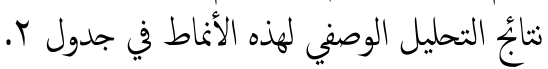

- - لم يستطع الباحث من تطبيق أدوات الدراسة تطبيقا

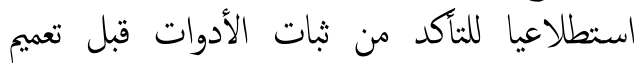

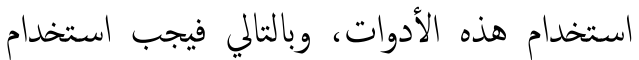

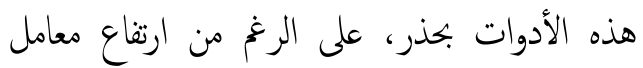
ثبات الذي نتج من التطبيق الفعلي للأدوات.

\section{نتاجُ الدراسة}

في الجزء التالي يعرض الباحث النتاجُ النحليلية لدراسة الحالة، وذلك تمهيدا للإجابة عن أسئلة الدراسة والتحقق من صحة النحة الفرضيات السابق عرضها. أولا: الإجابة عن السؤال الأول: ينص السؤال الأول في

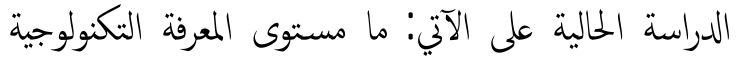

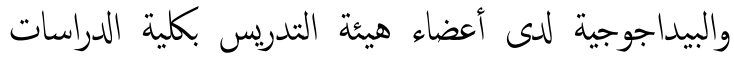

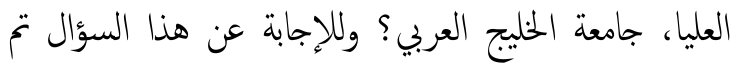

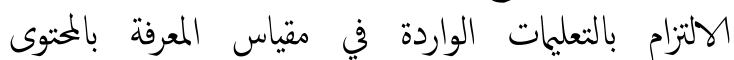

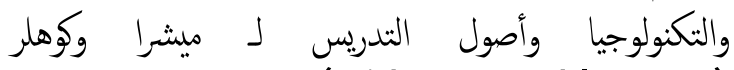
(Mishra \& Koehler, 2006) ) حيث تم تجميع المفردات المخصصة كلكل بعد من الأبعاد الستة بالمقياس' بعد المعرفة

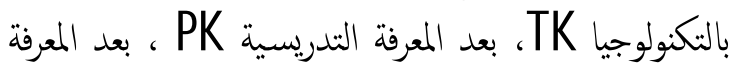

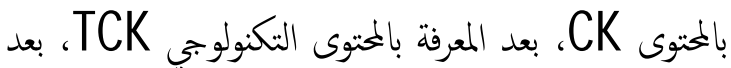

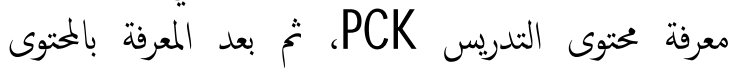
والتكنولوجيا وأصول التدريس TPCK. وتظهر نتائح التحليل الوصفي تفاوتا ملحوظا في المتوسطات وغير ملحوظ في ولني

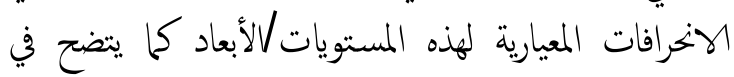

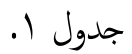
يتضح من جدول ا أن المعرفة التدريسية (البيداجوجية)

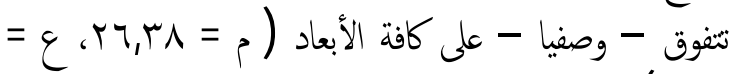

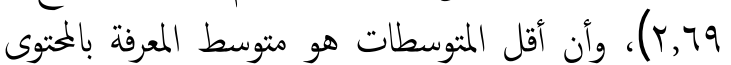

\section{جدول 1}

المتوسطات والانحرافات المعيارية لاستجابات عينة الدراسة على مقياس أبعاد المعرفة التكنولوجية والبيداجوجية

\begin{tabular}{|c|c|c|c|}
\hline \multicolumn{2}{|c|}{ الإحصاءات } & \multirow[t]{2}{*}{ 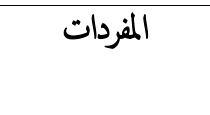 } & \multirow[t]{2}{*}{ أبعاد المعرفة التكنولوجية والبيداجوجية } \\
\hline الانحراف المعياري اع) & المتوسط (م) & & \\
\hline$r, q r$ & $19, £ 1$ & من ا إلى 0 & إ.المعرفة التكنولوجية TK \\
\hline$r, 79$ & r7, ז人 & من 7 إلى 11 & PK بالمعرفة التدريسية PK \\
\hline r,or & $10, \Sigma 0$ & من r إإلى 10 & CK.المعرفة بالمحتوى \\
\hline$r, \uparrow \cdot$ & $|7, r|$ & من 17 إلى 19 & عـالمعرفة بالمحتوى التكنولوجي TCK \\
\hline$r, r V$ & $10, \mathrm{V9}$ & 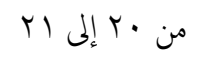 & P.المعرفة بالمحتوى التدريسي PCK \\
\hline r,V $\mathrm{Y}$ & $|\Lambda, r|$ & 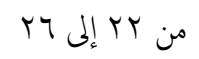 & TPCK المعرفة بالمحتوى والتكنولوجيا والثدريس \\
\hline
\end{tabular}




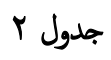

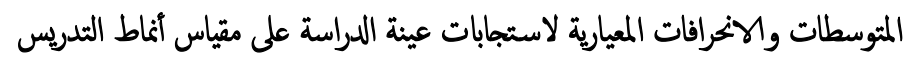

\begin{tabular}{|c|c|c|c|}
\hline الانحراف المعياري اع) & المتوسط (م) & القترات & أنماط التدريس \\
\hline $1, \varepsilon \varepsilon$ & $I V, V Y$ & $r^{\prime}, I V ، I T_{6} I$ & (.نمط المعلم المرن (المتكيف) \\
\hline I,A $\mathrm{V}$ & $17, \Upsilon 1$ & $19 ، 17 ، r, r$ & rir انطط المعلم المتمركز حول المتعلم \\
\hline$r, 01$ & $1 r, q$. & $r \varepsilon, r r, \Lambda, \varepsilon$ & "r.نط المعلم الموجه بالمنهج الرسمي \\
\hline$r, 10$ & $10,1 \varepsilon$ & $r r \cdot 10,11.1$. & عننط المعلم المتمركز حول الحقائق المستقلة \\
\hline$r, 10$ & $10,1 \varepsilon$ & $Y 1,1 \varepsilon ، 9, V$ & 0.نط المعلم الجماهيري \\
\hline$r, 0 \wedge$ & 9,1 . & $11,1 \pi \cdot 7,0$ & ب.بنط المعلم أحادي الوجمة \\
\hline
\end{tabular}

مستقل (تصنيفي) له مستويانי وفي ضوء طبيعة هذه

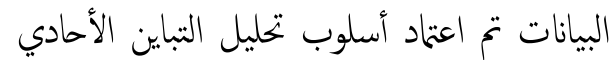

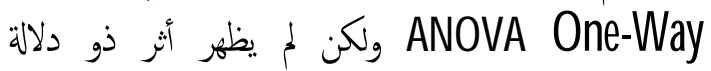
إحصائية عند مستوى 0., •. على مقياس أبعاد المعرفة

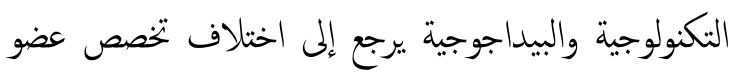

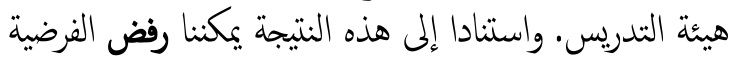
الأولى بالدراسة، ومن ثم يكون قد تم الإجابة عن السؤال الثالث بالدراسة.

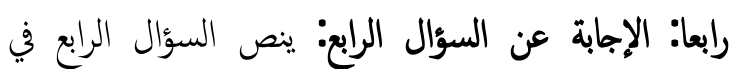

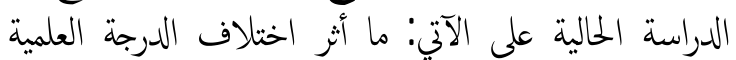

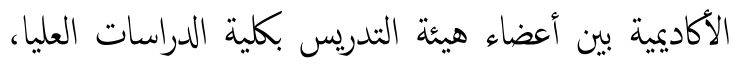

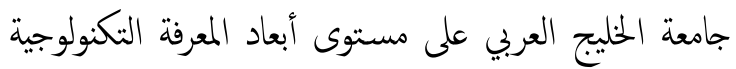

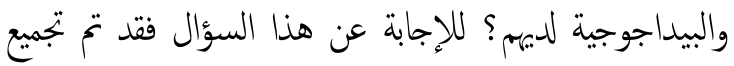
استجابات أفراد العينة على مقياس أبعاد المعرفة التكنولوجية لإجاتية

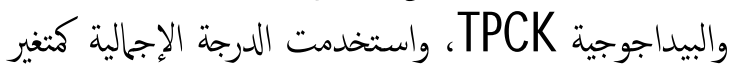

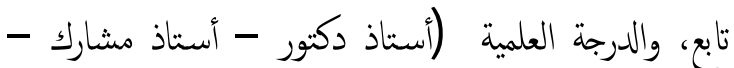
أستاذ مساعد) كتنغير مستقل (تصنيفي) له ثلاثة مستويات. وفي ضوء طبيعة هذه البيانات تم اعتاد أسلوب تحليل التباين

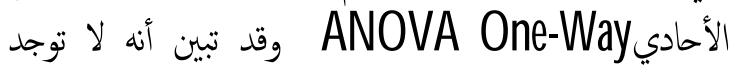

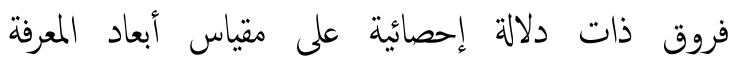

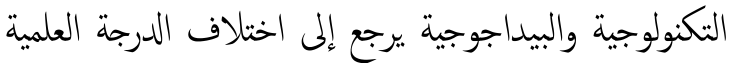

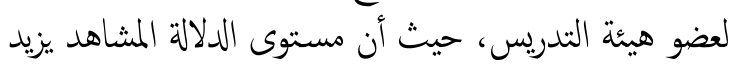

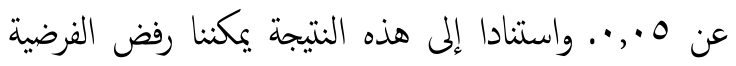
الثانية بالدراسة، ومن ثم يكون قد تم الإجابة عن السؤال الرابع بالدراسة.

خامسا': الإجابة عن السؤال الخامس' ينص السؤال الخامس الخس

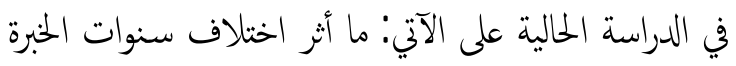

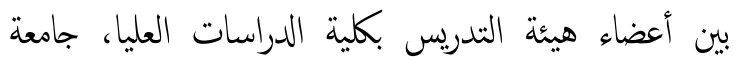

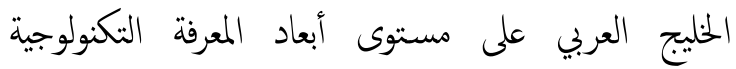

يتضح من جدول r أن متوسط النمط الأول (المعلم المرن)

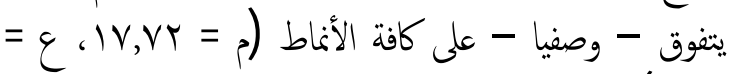

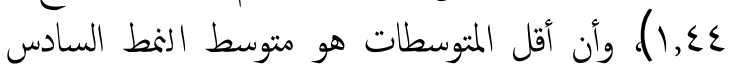

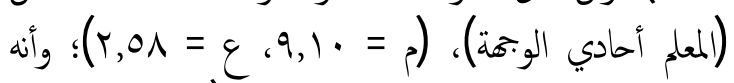

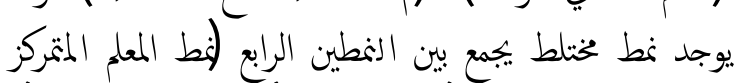

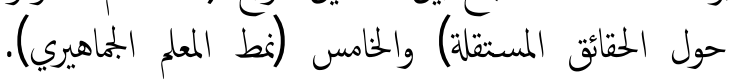

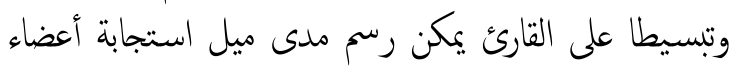

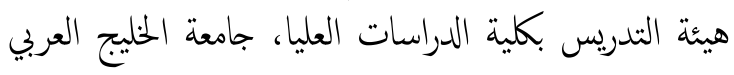

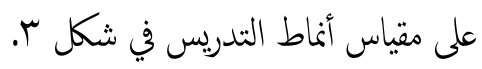

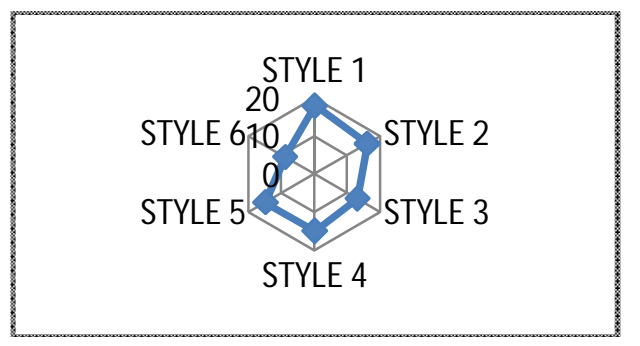

شكل rأ مدى ميل استجابة أعضاء هيئة التدريس على مقياس أثماط التدريس

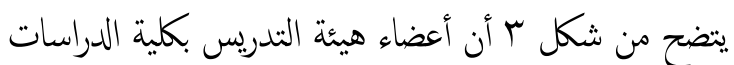

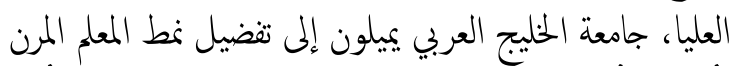

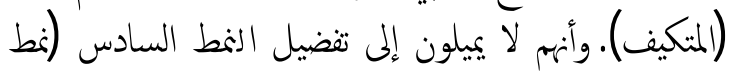

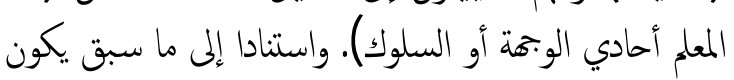
قد تح الإجابة عن السؤال الثاني من أسئلة الدراسة.

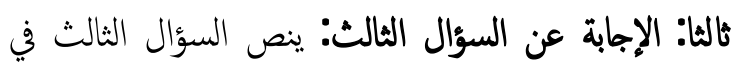

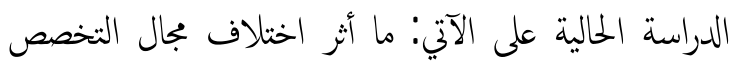

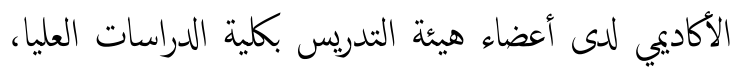

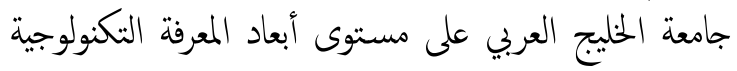

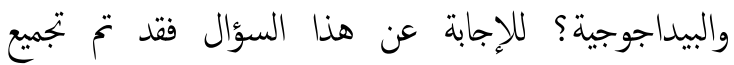
استجابات أفراد العينة على مقياس أبعاد المعرفة التكنولوجية المالية والبيداجوجة TPCK واستخدمت الدرجة الإجالية كمتغير كناب، وبجال النخصص (دراسات تقنية - دراسات تربوية) كتنغير 
الفرضية الرابعة بالدراسة الحالية جزئيا، وبالتالي يكون قد تح الإجابة عن السؤال السادس بالدراسة الحالية.

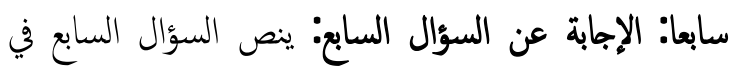

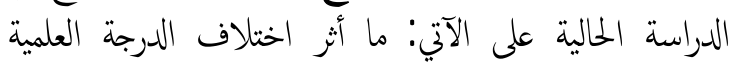

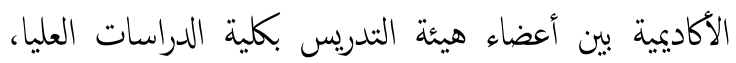

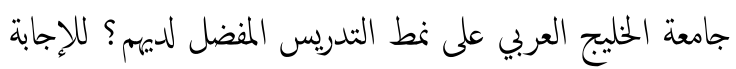

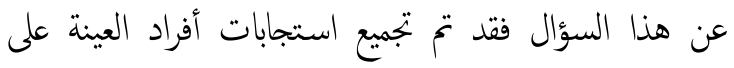

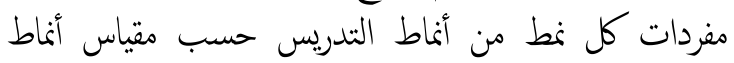

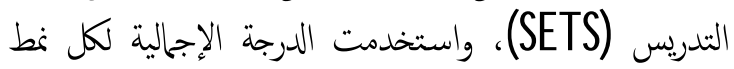

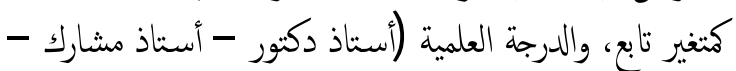
أستاذ مساعد) كتنغير مستقل (تصنيفي) له ثلاثة مستويات. وفي ضوء طبيعة هذه البيانات تم اعتماد أسلوب تحليل التباين

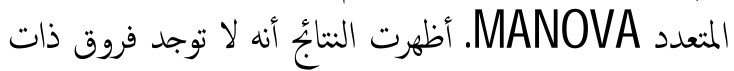

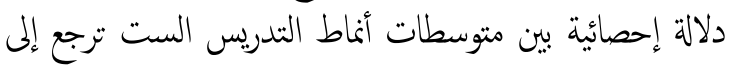

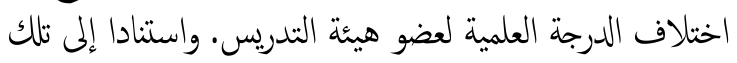

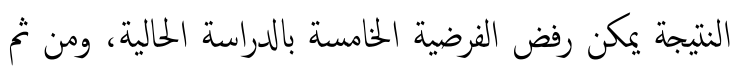
يكون قد تم الإجابة عن السؤال السابع بالدارسة. ثامنا: الإجابة عن السؤال الثامن: ينص السؤال الثامن في

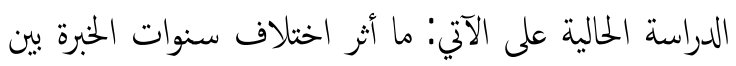

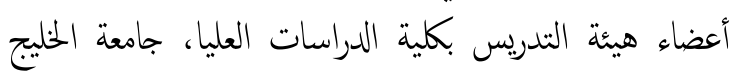

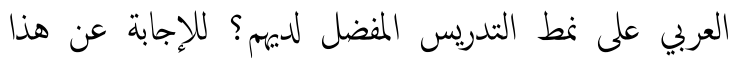

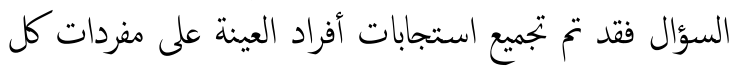

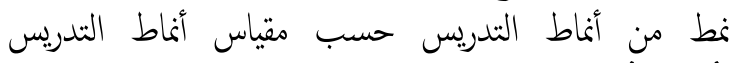
(SETS)

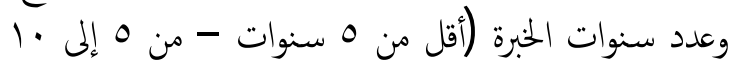

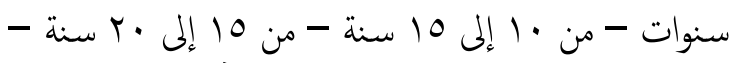

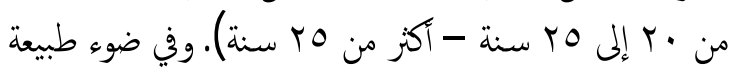

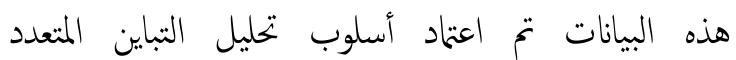

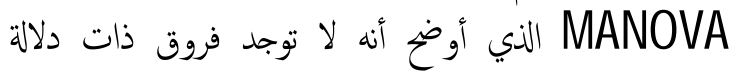

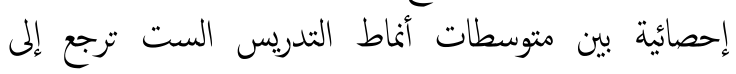

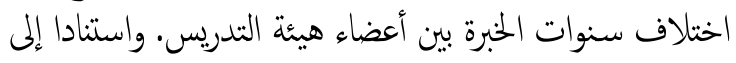
تلك النتيجة يككن رفض الفرضية السادسة بالدراسة الحالية، ومن ثخ يكون قد تم الإجابة عن السؤال الثامن بالدارسة. تاسعا': الإجابة عن السؤال التاسع' ينص السؤال التاسع في

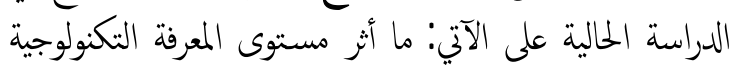

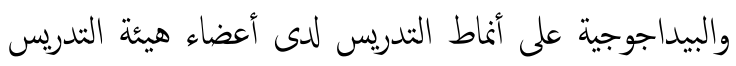

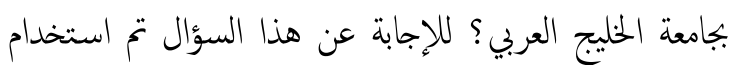

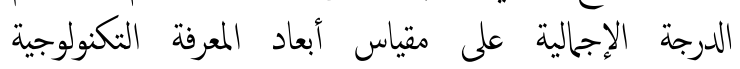

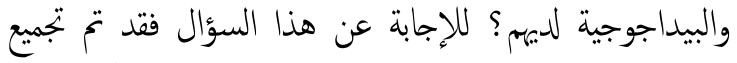
استجابات أفراد العينة على مقياس أبعاد المعرفة التكنولوجية لإجية

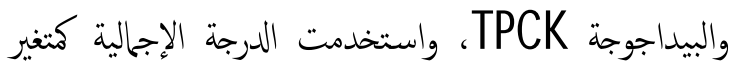

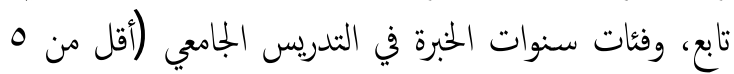

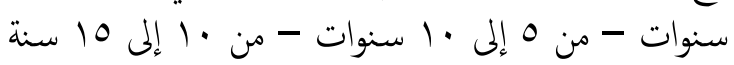

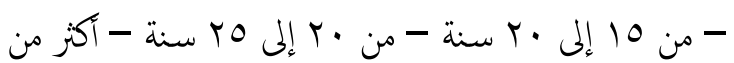

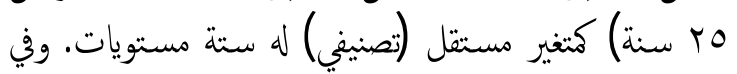

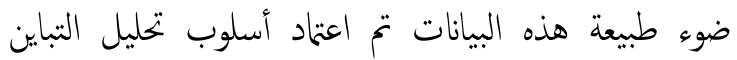

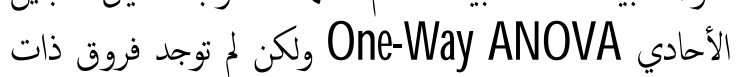
دلالة إحصائية في استجابات أفراد العينة على مقياس أبعاد

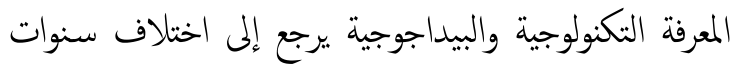

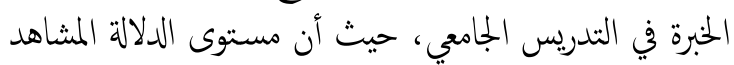

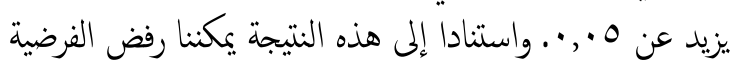

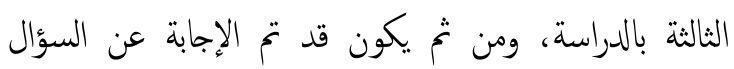
الخامس بالمراسة.

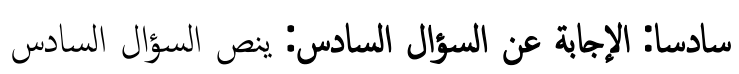

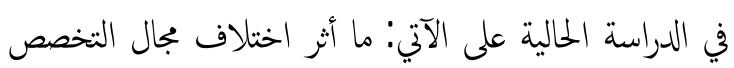

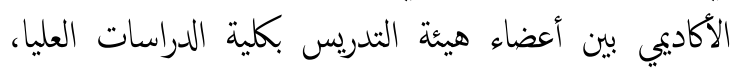

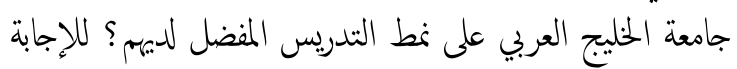

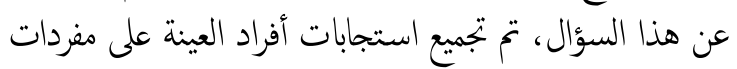

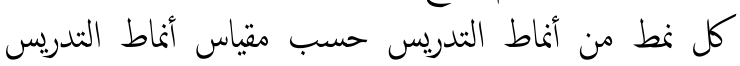

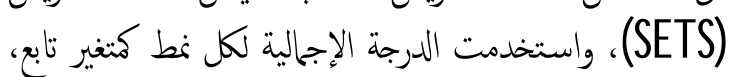

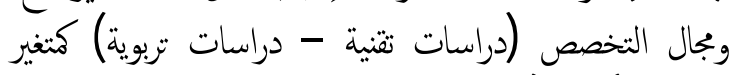

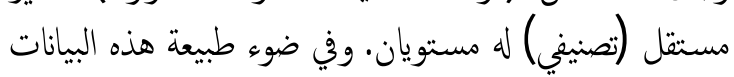
تم اعتماد أسلوب تحليل التباين المنعدد MANOVA. ويتضح من جدول ب أنه لا توجد فروق بين أنماط التدريس

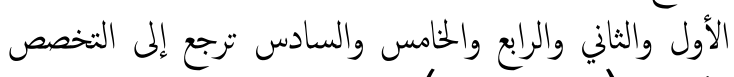

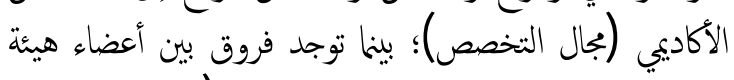

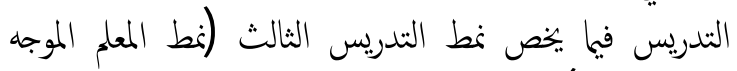

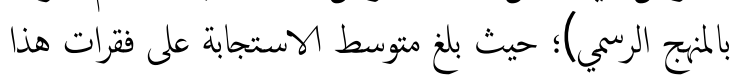

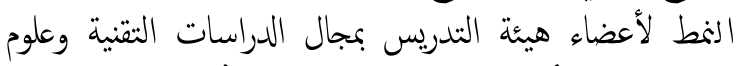

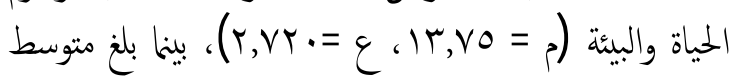
الاستجابة على فقرات هذا النمط لأعضاء هيئة التدريس بمجال

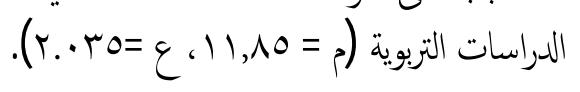
وتشير هذه النتيجة إلى أن أعضاء هيئة التدريس بمجال

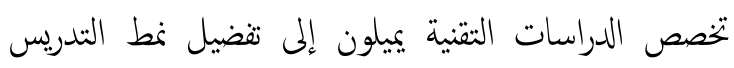
الموجه بالمنهج الرسمي أكثر من أعضاء هيئة التدريس بمجال

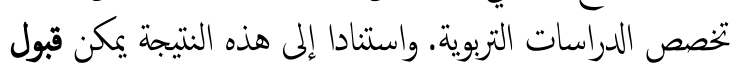




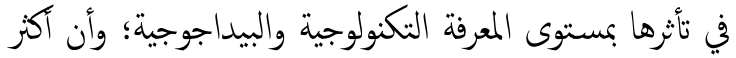

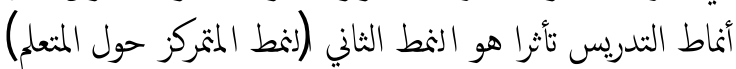

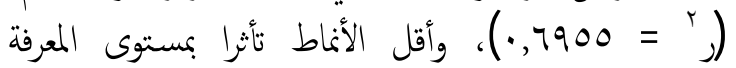

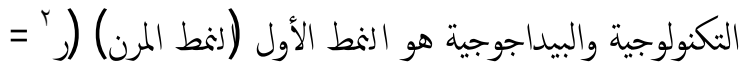

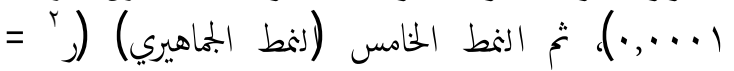

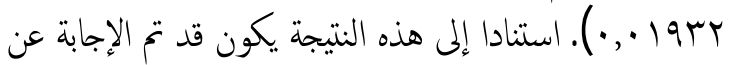

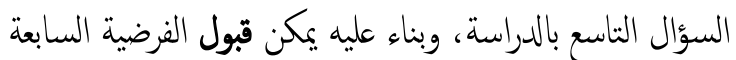

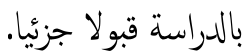

والبيداجوجية، والدرجة الإجالية على مقياس أنماط الندريس.

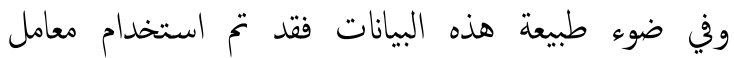

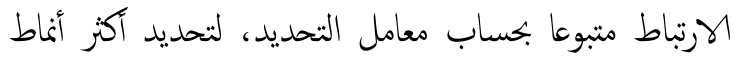

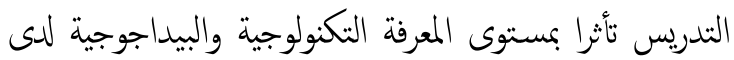
أعضاء هيئة التدريس بكلية الدراسات العليا، جامعة الخليج

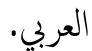

يتضح من جدول ع أن أنماط الندريس لدى أعضاء هيئة

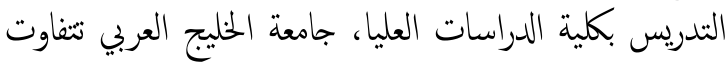

\section{جدول rإ ب}

\begin{tabular}{|c|c|c|c|c|c|c|}
\hline مستوى الدلالة & قيمة ف & متوسط المربعات & درجات الحرية & بمموع المربعات & أثماط التدريس & بيان \\
\hline$\cdot, \Gamma 7\rceil$ & $\cdot, 170$ & 1,var & 1 & $1, \mathrm{~V} 9 \mathrm{r}$ & لنمط الأول & بين المجموعات \\
\hline r & I, $\vee \wedge$. & $7, \cdot \varepsilon_{\Lambda}$ & 1 & $7, \cdot \sum \wedge$ & لنمط الثاني & (بجال التخصص) \\
\hline$\cdot, \cdot \leq 7$ & $\varepsilon, r \backsim \Lambda$ & ro, 99V & 1 & ro,99V & لنمط الثالث & \\
\hline . OY. & - & $r, \cdots r$ & 1 & $r, \cdots r$ & لنمط الرابع & \\
\hline • & $\cdot, 10$. & $\Lambda, \sum \uparrow \Lambda$ & 1 & $\Lambda, \sum 7 \Lambda$ & لنمط الخامس & \\
\hline \multirow[t]{13}{*}{$\cdot, 9 T V$} & $\cdot, \cdots q$ & $\cdot, \cdot 7$. & 1 & $\cdot, \cdot 7$. & لنمط السادس & \\
\hline & & $T, \cdot V \varepsilon$ & TV & $07, \cdots$ & لنمط الأول & داخل المجموعات \\
\hline & & $r, r q \Lambda$ & TV & $91, v \leqslant 0$ & لنمط الثاني & \\
\hline & & $0,90 \mathrm{r}$ & TV & $17 \cdot, 794$ & لنمط الثالث & \\
\hline & & $\varepsilon, V Y$. & TV & $I V Y, \Sigma \varepsilon Y$ & لنمط الرابع & \\
\hline & & 9,974 & TV & $r \checkmark \Lambda, q \wedge 1$ & لنمط الخامس & \\
\hline & & 7,911 & TV & |人ฯ, Tr. & لنمط السادس & \\
\hline & & & & ov,Vqr & لنمط الأول & التباين الكلي \\
\hline & & & & $q \vee, v q r$ & لنمط الثاني & \\
\hline & & & & $1147,79$. & لنمط الثالث & \\
\hline & & & & $\mid r q, \varepsilon \varepsilon \wedge$ & لنمط الرابع & \\
\hline & & & & $T V V, \varepsilon \varepsilon \lambda$ & لنمط الخامس & \\
\hline & & & & $1 \wedge 7,79$. & لنمط السادس & \\
\hline
\end{tabular}

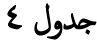

معامل الارتباط ومعامل التحديد بين مستوى أبعاد المعرفة النكنولوجية والبيداجوجية وأماط التدريس المفضلة لدى أعضاء هيئة التدريس

\begin{tabular}{|c|c|c|c|}
\hline قيمة معامل التحديد ار' T & تيمة معامل الارتباط (ر) & المتغير التابع (أنماط التدريس] & المتغير المستقل \\
\hline$\cdot, \cdots$ & $\cdot \cdot, \cdot 1 r$ & لنمط الأول: المعلم المرن & الدرجة الإجالية على مقياس \\
\hline$\cdot, 797$ & *.,人 & لنمط الثاني: المعلم 'لمتركز حول المتعلم & أبعاد المعرفة التكنولوجية \\
\hline$\cdot, .01$ & $\cdot$, YYO & لنمط الثالث': المعلم الموجه بالمنهج الرسمي & والبيداجوجية \\
\hline$\cdot, 1 \mathrm{hV}$ & $*, r v \cdot$ & لنمط الرابع: المعلى الموجه بالحقائق المستقلة & \\
\hline$\cdot, .19$ & $\cdot, 119$ & لنمط الخامس: المعلم الجماهيري & \\
\hline$\cdot, \cdot \wedge v$ & $\cdot, 190$ & لنمط السادس: المعلم أحادي الوجهة والسلوك & \\
\hline
\end{tabular}


في الدراسة - قد سعوا لتطوير أدائم التدريسي والتكنولوجي

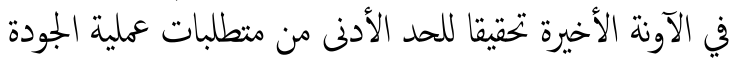

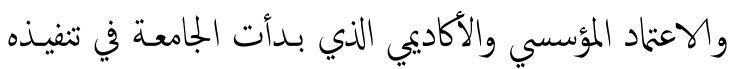

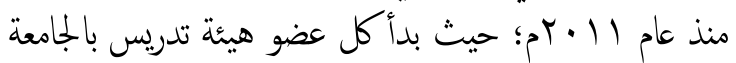

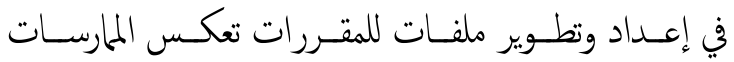

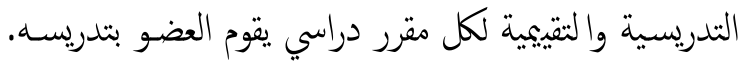

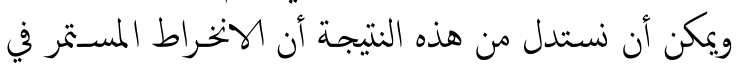
تطوير ملفات المقرر Course Portfolios ما - من مستوى الوعي التدريسي والتكنولوجي لدى أعضاء

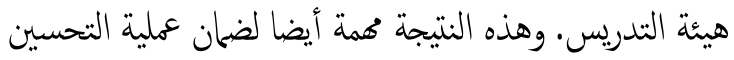

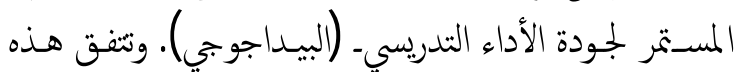
النتيجة مع نتيجة دراسة ستودارت (Stoddart, 2006) التي

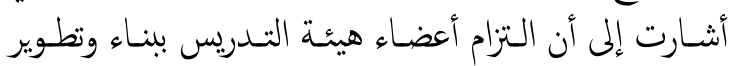

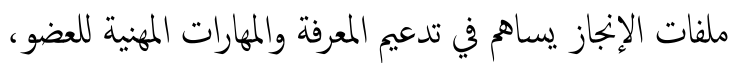

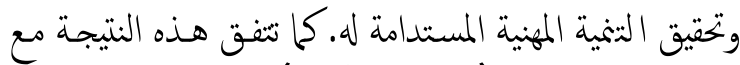

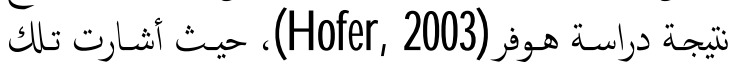

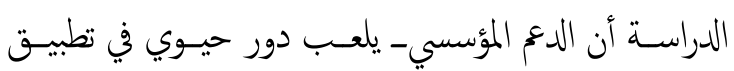
معايير التدريس والتكنولوجيا.

وأظهرت نتائُ تحليـل البيـانات بالدراسة الحاليـة عدم وجـود

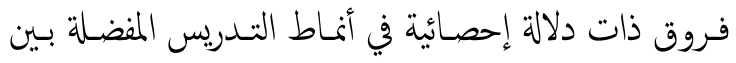

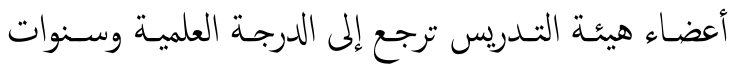

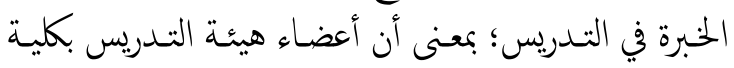

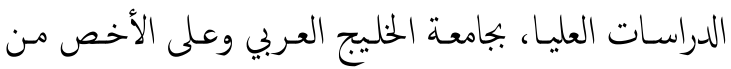

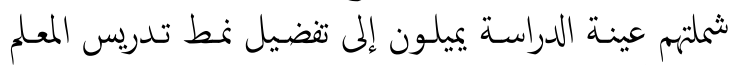

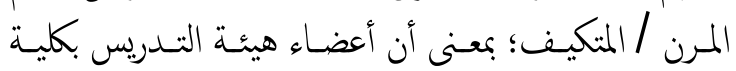

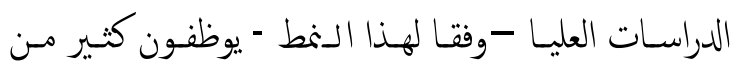

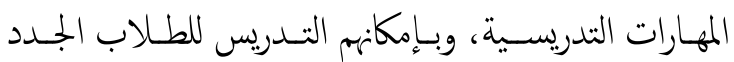

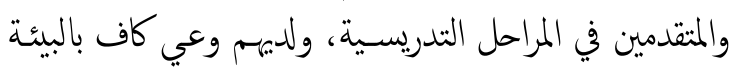

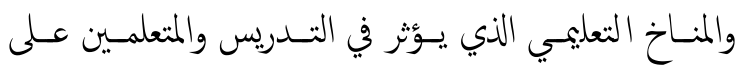

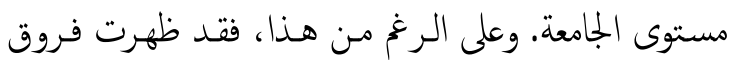

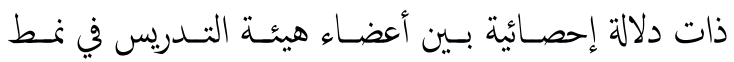

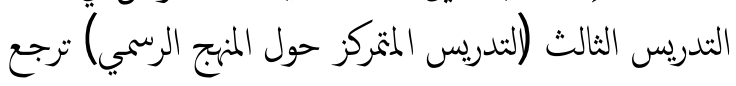

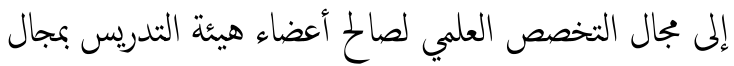

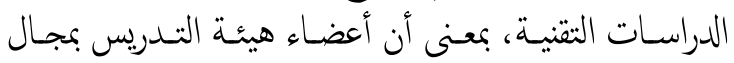

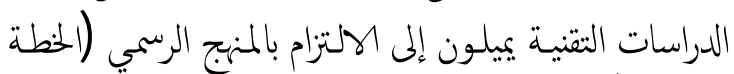

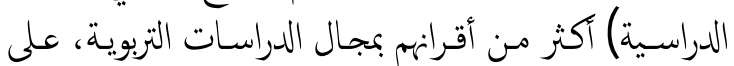

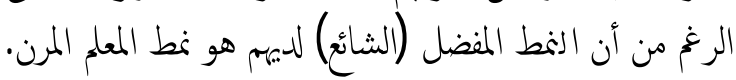

بالإضافة إلى ما سبق، فقد كان مخططا استخدام اختبار مربع

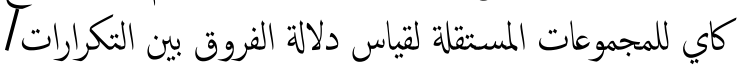

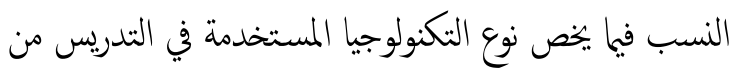

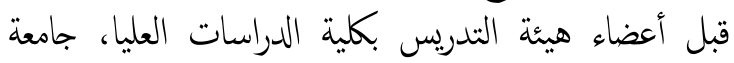

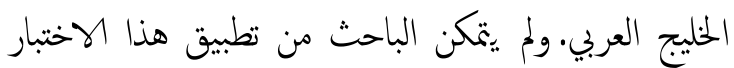

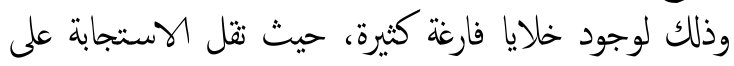

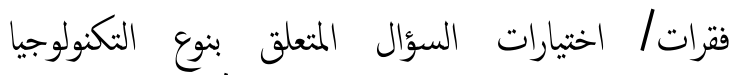

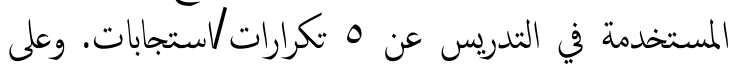

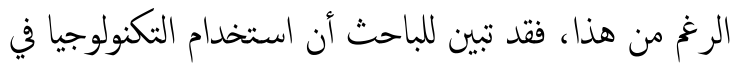
التدريس من قبل أعضاء هيئة التدريس بكلية الدراسات العليا

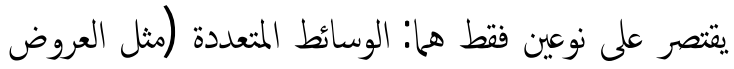

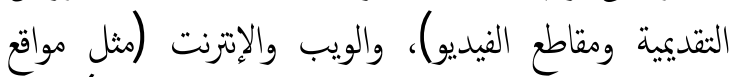

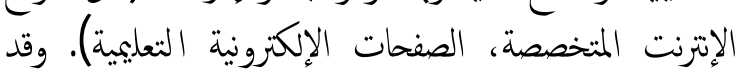

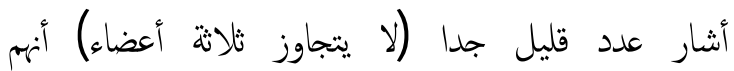

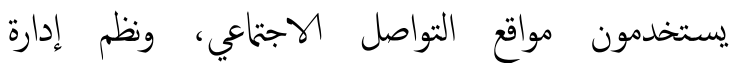

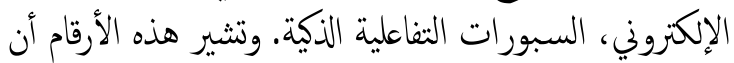

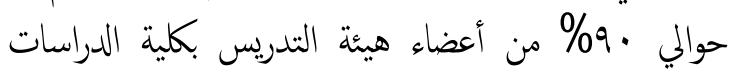

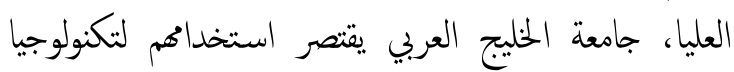

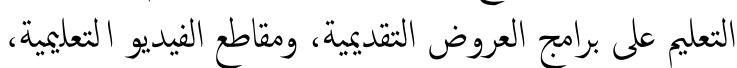

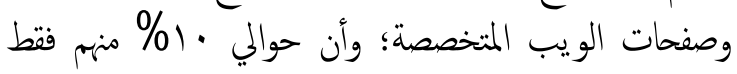

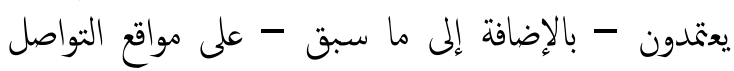

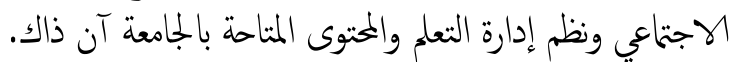

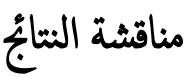

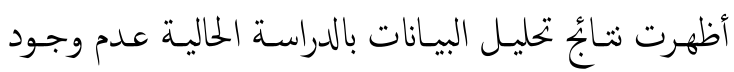

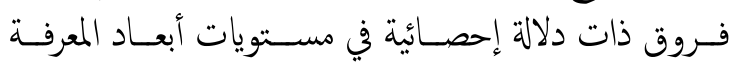

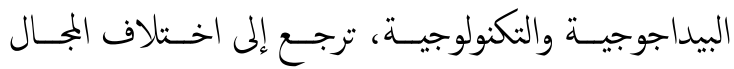

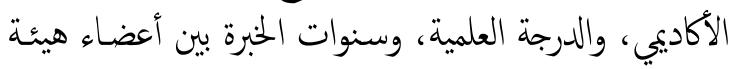
التـدريس بكليـة الدراسـات العليـا، جامعـة الخلـيج العـربي.

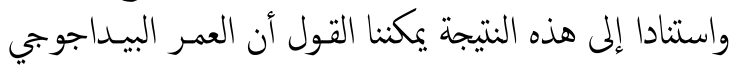

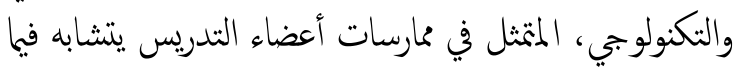
بينهم، بصرف النظر عن سنوات الخبرة في التدريس الجامعي. بمعنى أن أعضاء هيئة التدريس بكلية الدراسات العليا، جامعة لئية

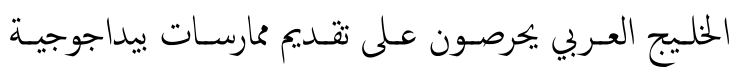
وتكنولوجية مقبولة في ضوء ما هو متاح من أدوات تكنولوجيا

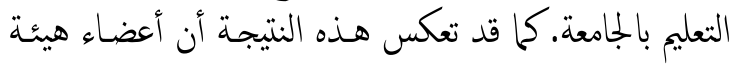

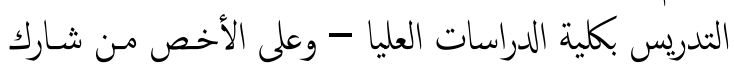


الإلكتروني المتقدمة لا تعكس هذا الوعي؛ الأمر الذي يتوجب

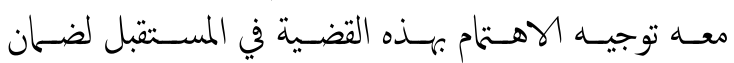

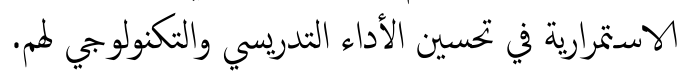

التوصيات

في ضوء ما تقدم من نناجُ، وفي ضوء المناقشة السابقة، يوصي الباحث بما يلي' أولا' تطوير خطة للتنمية المهنية المستدامة لأعضاء هيئة

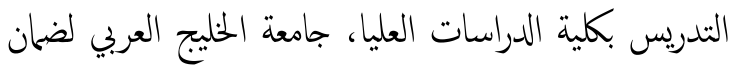

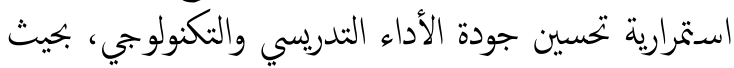
تعتمد هذه الخطة الإستراتيجية على نماذج ومداخل تحسين

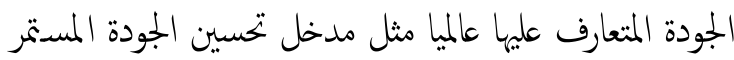

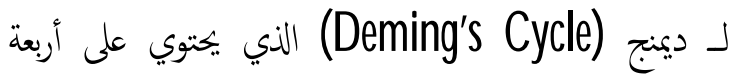

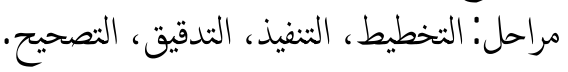
ثانيا' تطوير خطة إستراتيجية لضمان جودة دمج تكنولوجيا

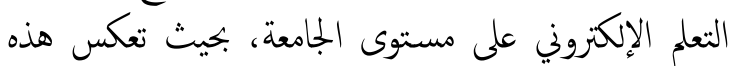

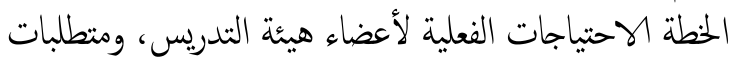
وآليات تحتقها.

ثالثا' بناء مجتمعات التعلم الإلكنروني على مستوى الجامعة

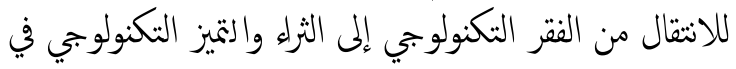

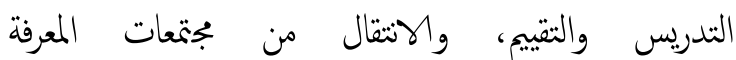
Communities of Inquiry Communities of Practice

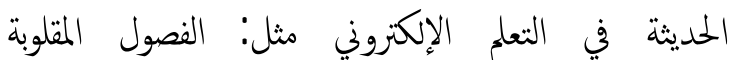
Flipped Classrooms Smart Technologies \& Intelligent Tutoring E-books Systems والكنب الإنكنرونية. رابعا': تطوير منظومة للتقييم الإنكتروني على مستوى الجامعة University-wide Assessment System مؤشرات إلكترونية لمخرجات عملية التعلم على مستوى البرامج Programs Intended Learning Outcomes Courses Intended ، والمقررات الدراسية (PILOS) L Learning Outcomes (CILOS)

خامسا: تطوير الحضانات الإلكترونية والبيداجوجية لضمان

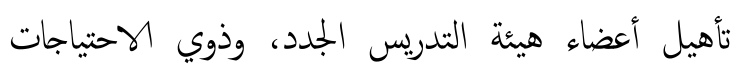

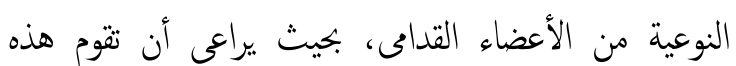

كما أنه يوجد نمط تدريس مختلط بين أعضاء هيئة التدريس

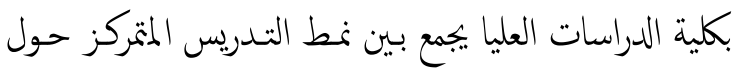

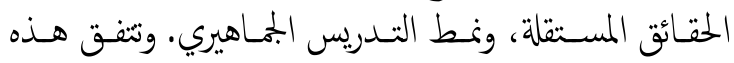

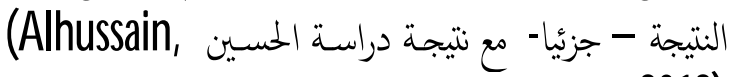

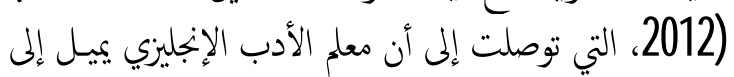

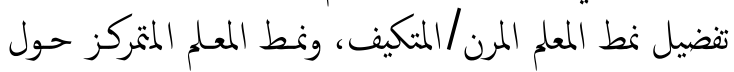

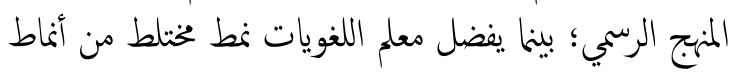

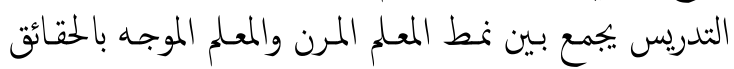
التعليمية، ونط المعلم المحاهيري.

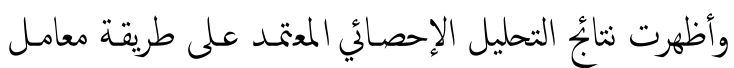

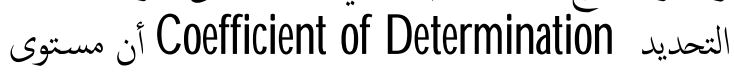

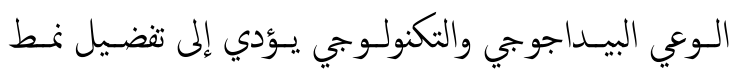

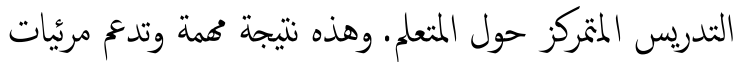

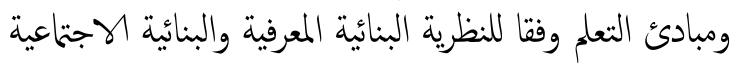

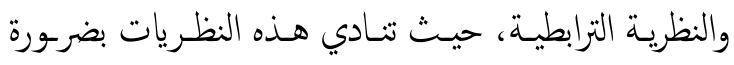

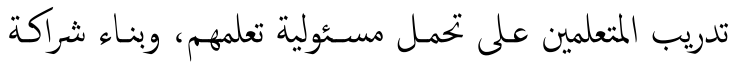

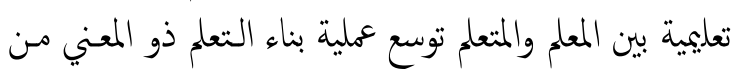

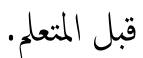
أثنارت نتائُ تحليـل البيـانات في الدراسـة الحالية أن الغالبيـة

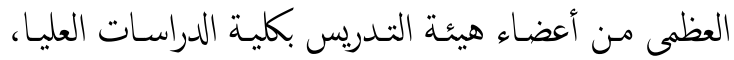

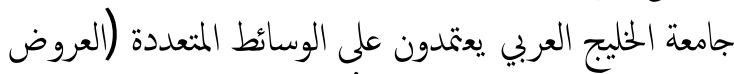

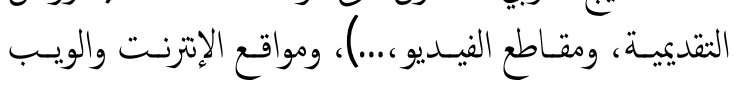

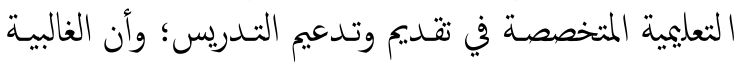

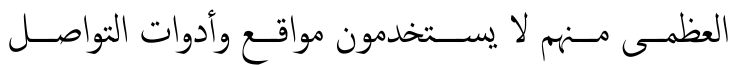

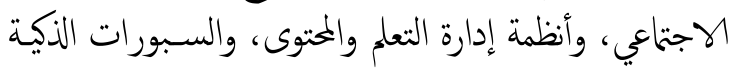

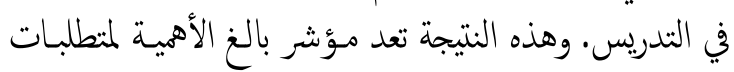

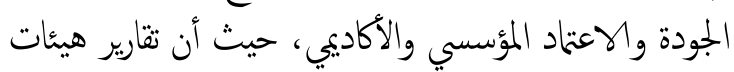

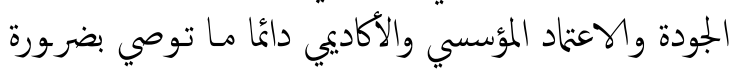

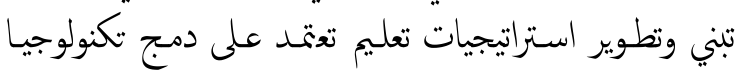

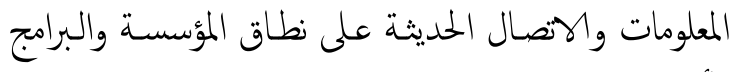
الأكاديمة. وخلاصة القول، فإن أعضاء هيئة التـدريس بكليـة الدراسـات

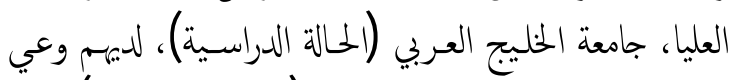

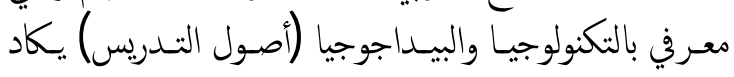

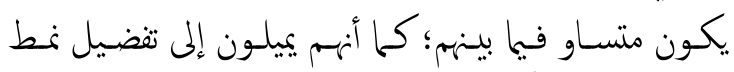

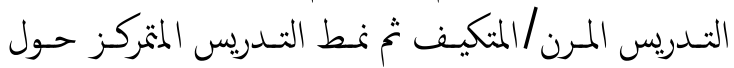

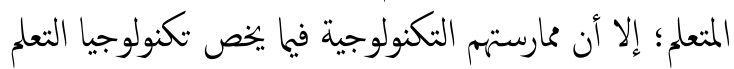




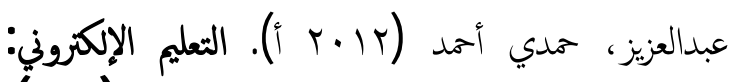

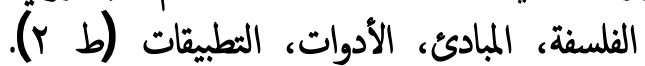
الأردن: درا الفكر.

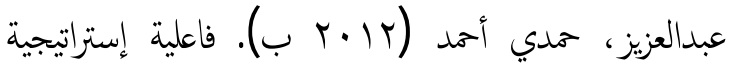

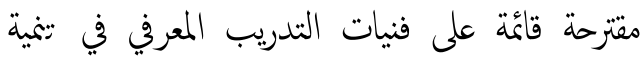
مهارات تصميم التدريس الإلكتروني وتحسين المعتقدات

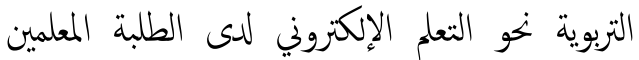

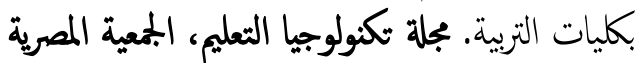
لتكنولوجيا التعليم، بحث مقبول المنشر، أكتوبر $r \cdot T$

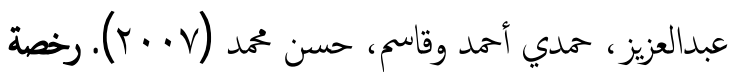
التدريس' رؤية لتطوير معايير التدريس. الأردن' دار الفكر.

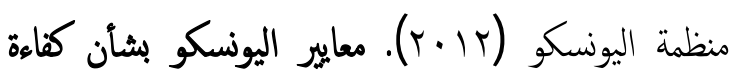
المعلمين في مجال تكنولوجيا المعلومات والماتصال متاح في: WWW.cst.unesco-ci.org،

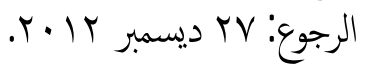

Abdelaziz, H. A. (2013). From content engagement to cognitive engagement: Toward an immersive Web-based learning model to develop self- questioning and self-study skills. International Journal of Technology Diffusion, 4(1), 16-32, JanuaryMarch 2013.

Alhussain, A. M. (2012). Identifying teaching style: The case of Saudi college English language and literature teachers. English Language T eaching, 5(8), 122-129.

Diaz, V., Garrett, P. B., Kinely, E. R., Moore, J. F., Schwart, C.M., \& Kohrman, P.(2009). Faculty Development for the 21st Century. EDUCAUSE Review, 44(3):46-55. Retrieved from http:/ / www.educause.edu/ ero/ article/ fa culty-development-21st-century

Dillman, D. (2000). M ail and internet surveys: The tailored design method (2nd ed.). NY: John Wiley \& Sons, Inc.

Evans, C., Harkins, M., \& Young, J. (2008). Exploring teaching styles and cognitive styles: Evidence from school teachers in Canada. North American Journal of Psychology,

10(3),

567-582.
الحضانات على أسس النعلم وفقا لنظرية تعليم الكبار ونظرية

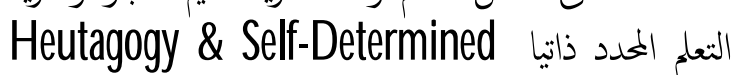

Learning

في ضوء ما تم التوصل إليه من نتائ، وفي ضوء المناقشة

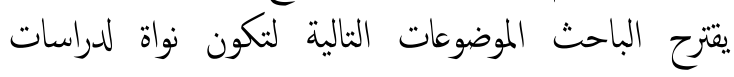
مستقبلية امتدادا للدراسة الحالية.

ا ا تقويم البرامج التدريية المقدمة لأعضاء هيئة التدريس

بالجامعات في ضوء مدخل تحسين الجودة لـ ديمنج لضان جودة التدريس المعتمد لخدين (Deming's Cycle) على التكنولوجيا.

r فاعلية الحضانات البيداجوجية والتكنولوجية في تنمية كفايات التدريس والتكنولوجيا لدى أعضاء هيئة التئة

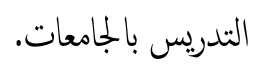
r. تصميم برنامج تدريبي لتنمية محارات التدريس الإبداعي لدى أعضاء هيئة التدريس بالجامعات.

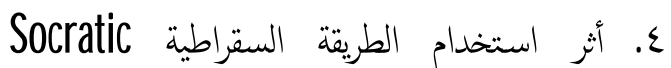
Seminar أعضاء هيئة التدريس بالجامعات.

\section{المراجـ}

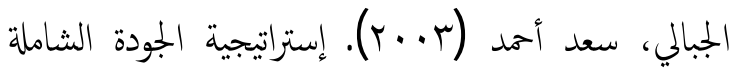

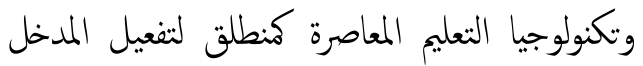

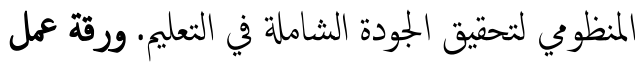

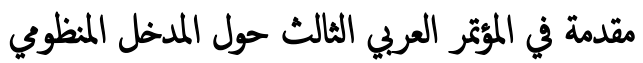

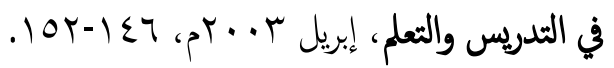

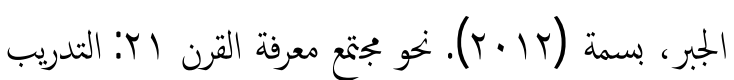

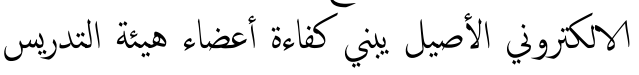
في النعليم العالي، ورقة عمل مقدمة في الندوة العلمية الأولى في التدريب الإلكروني وفرص تحسين الأداء،

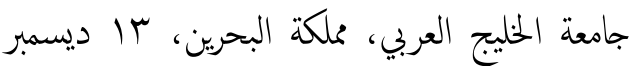
. ITN-Itr ،

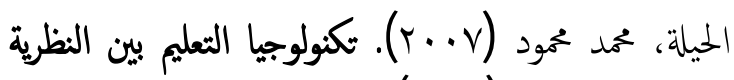

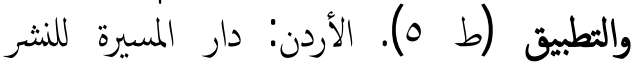
والتوزيع والطباعة. 
Guzey, S. S. \& Roehrig, G. H. (2009). Teaching science with technology: case studies of science teachers' development of technological pedagogical content knowledge (TPCK). Contemporary Issues in Technology and Teacher Education, 9(1), 2545.

Harris, J., Mishra, P., \& Koehler, M. (2009). Teachers' technological pedagogical content knowledge and learning activity types: curriculum-based technology integration reframed. Journal of Research on Technology in Education, 41(4): 393-416.

Henard, F. (2009). The path to quality teaching in higher education. Retrieved on May 18 $8^{\text {th }}, 2014$ from:

http:/ / www.oecd.org/ edu/ imhe/ 441502 46.pdf

Hein, V., Ries, F., Pires, F., Caune, A., Emeljanovas, A., Heszteráné, F., \& Valantiniene, I. (2012). The relationship between teaching styles and motivation to teach among physical education teachers. Journal of Sports Science and M edicine 11, 123-130.

Hofer, A. J. (2003). ISTE educational technology standards: Implementation in award-winning teacher education programs. Doctoral Diss. University of Virginia, USA.

International Society for Technology in Education (ISTE). (2009). N ational educational technology standards for teachers: Preparing teachers to use technology. Eugene, OR: A uthor.

Jarvis, P. (1985). Thinking critically in an information society: A sociological analysis. Lifelong-Learning, 8(6), 11-14.

Kauchak, D. \& Eggen, P. (1998, 3 ed.). Learning and teaching: Research based methods. Allen and Bacon.

Kenney, J. L., Banerjee, P., \& Newcombe, E. (2010). Developing and sustaining positive change in faculty technology skills: lessons learned from an innovative faculty development initiative. International Journal of Technology in Teaching and Learning, 6(2): 89-102.

Koehler, M. J., \& Mishra, P. (2009). What is technological pedagogical content knowledge? Contemporary Issues in
Technology and Teacher Education, 9(1), 6070.

Krause, B., Barrie, S., \& Scott, G. (2012). Mapping learning and teaching standards in Australian higher education: An issues and options paper. Teaching and Learning Standards: Issues and options paper - Feb 2012. Retrieved from: http:/ / www.uws.edu.au/ data/ assets/ pdf file/ 0008/ 294137/ KerriLee website.p df

Mishra, P., \& Koehler, M. J. (2006).Technological pedagogical content knowledge:a framework for teacher knowledge.T eachers College Record, 108 (6): 1017-1054.

M ohanna, K., Chambers, R., \& Wall, D. (2007). The self evaluation tool: The Staffordshire evaluation of teaching styles. Staffordshire University, UK.

M ohanna, K., Chambers, R., \& Wall, D. (2007). Your teaching style: A practical guide to understanding, developing and improving. UK, Raddliffe Publishing Ltd.

Mohanna, K., Cottrell, E., Wall., \& Chambers, R. (2011). D eveloping your teaching style and techniques. Retrieved on 21/ 12/ 2013 from: http:/ / www.radcliffehealth.com/ sites/ ra dcliffehealth.com/ files/ books/ samplecha pter/ 5322/ RAD-JONES-11-0305-01167221100rdz.pdf

National Board for Professional Teaching Standards (NBPTS). (1993). W hat teachers should know and be able to do. Detroit: NBPTS, A uthor.

National Council for Accreditation of Teacher Education (NCATE). (1996). NCATE public opinion poll. Washington, D.C: NCATE, Author.

National Educational Technology Standards for Students (NETS). (2000). Connecting curriculum and technology. International Society for Technology in Education, USA.

Opdenakker, M.C., \& Van Damme, J. (2006). Teacher characteristics and teaching styles as effectiveness enhancing factors of classroom practice. Teaching and Teacher Education, 22(1), 1-21.

Shin, T., Koehler, M., Mishra, P., Schmidt, D., Baran, E., \& Thompson, A. (2009). Changing technological pedagogical 
content knowledge (TPACK) through course experiences. In: I. Gibson et al. (Eds.), Proceedings of Society for Information Technology \& Teacher Education International Conference 2009, 4152-4159

Shulman, L. (1986). Those who understand: Knowledge growth in teaching. Educational Researcher, 15(2), pp 4-14.

Steffy, B., Wolfe, M., Pasch, S., \& Enz, B. (2000). Life cycle of the career teacher. Thousand Oaks, CA : Corwin Press Inc.

Stoddart, S. K. (2006). A study of electronic portfolio development in the school of education at $\mathrm{M}$ arian College. Doctoral Diss. Capella University, USA.

Stuart, C., \& Thurlow, D. (2000). Making it their own: Preservice teachers, experience, beliefs and classroom practices. Journal of Teacher Education, 51(29), 113-121.

The Higher Education Academy. (2003). The UK professional standards framework for teaching and supporting learning in higher education. Retrieved from: www.heacademy.ac.uk, on May 18th, 2014.

Tomlinson, C. A. (2005). Differentiated instruction as way to achieve equity and excellence in today's schools. Building inclusive schools: A search for solutions. Conference Report Canadian Teachers' Federation Conference (19-21). Ottawa, Ontario. 